$$
\begin{aligned}
& \text { د. دعود نامي سعود المربي }
\end{aligned}
$$

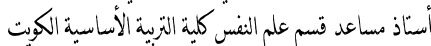

$$
\begin{aligned}
& \text { د.اصر نزال سهو الشمري } \\
& \text { أستّاذ مساعد قسم علم النفس كلمة التربة الأساسية الكونيت }
\end{aligned}
$$

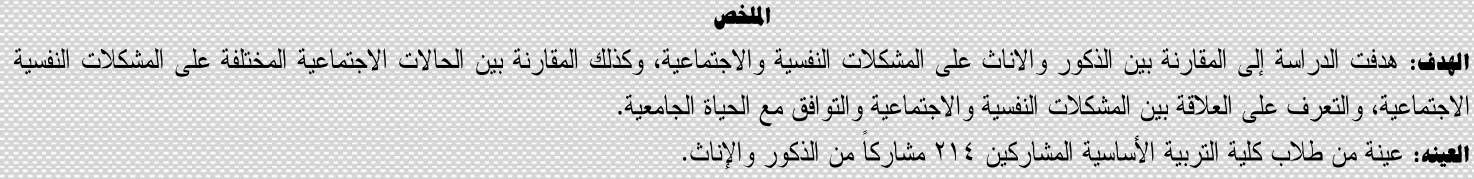

Psychological and Social Problems and their Relations to Patterns of Consistency with the University Life for Students of College of Basic Education in State of Kuwait

Aims: This study aims to compare between males and females in terms of the psychological and social problems, compare between the different social cases in terms of the psychological and social problems and define the relation between the psychological and social problems and the adapting to the university life

Sample: It consists of 214 (Male/ Female) students of Faculty of Basic Education.

Study Method: This study belongs to the qualitative- analytical type of studies, since its purpose is to depict and monitor the sociopsychological problems and their relation to coping with university life.

Statistical Approaches: the study has used some statistical approaches to check up validity of hypotheses, using: averages, standard deviations, t.test, for differences between two independent samples, ANOVA analysis, Pearson's coefficient correlation for defining the relationship between dimensions of the socio- psychological problems and adjustment to university life.

Instruments: Adjustment to College Scale (ATCS), by Robert Baker, Bohaden Siryk, 1984, Arabized and prepared by Abdel Salam, 2006. It is a multi-dimension instrument for self-report for quantative measurement of male/ female students' adjustment to university life.

Results: The results of the study reveal that there are differences concerning autism and personal problems for the favor of the males and there are differences concerning Self- concept, anger and emotional instability for the favor of the females. While there are no differences regarding expatriation and bareness or social status. Moreover, there is no correlational relation between the measurement of psychological and social problems and the adapting to the university life, while there is positive correlational relation between the self- concept problem and the academic consistency and commitment to goals achievement, between the emotional instability problem and the academic and personal consistency and commitment to goals achievement, and between the personal problems and the academic consistency and commitment to goals achievement. Furthermore, there is negative correlational relation between the expatriation and bareness problem and self-consistency, between anger and selfconsistency and between personal problems and self- consistency. 
الدراسية لاى طلاب المرحلة الجامعية، من ناحية، وتعل على تثبل الطلاب للحقائق

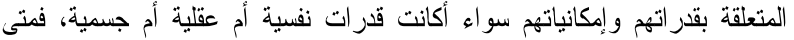

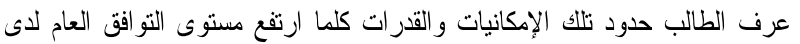

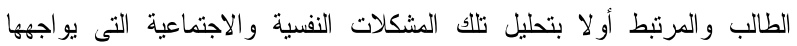
الطلاب للتعرف عليها، ثم التعرف على مدى تأثير هذه المشكلات على التوافق العام

لايهم ومدى إثباع هذا التو افق لاحتياجاتهم و اثشباعاتهم النفسية والاجتماعية.

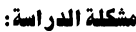

يو اجه كثير من الأفراد مشكلات في التكيف، خاصة طلاب المرحلة الجامعية،

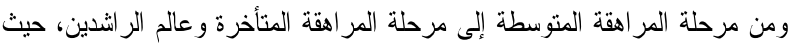

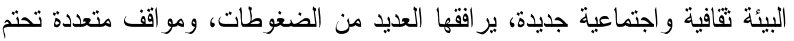

على الفرد الوصول إلى تكيف مثالي. ويعد التكيف مع الحياة الجامعية متطلبًا أساسيًا لنجاح الطلبة و استمر ارهم بالدر استة

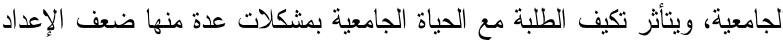
المسبق لاخول المرحلة الجامعية، اختلاف الجو الجامعي التعليمي عن الجو التعليمى لجئي

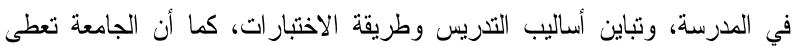

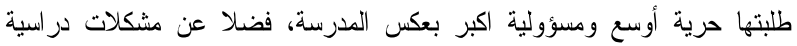

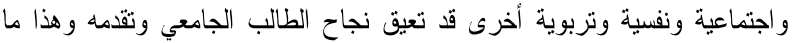

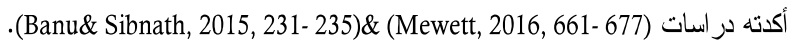
وقد لاحظ الباحثان بصفتهما أساتذه بكلية التربية الأساسية فى دولة الكويت أن

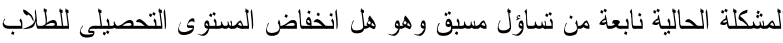

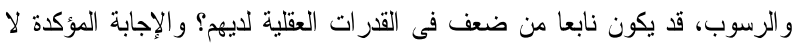
بالطبع فهو طالب جامعى لدية القدرة الأكاديمية التى تؤهله للنجاح وتخطى هذه

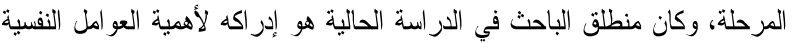

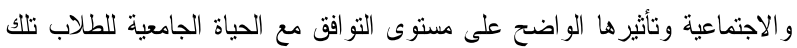

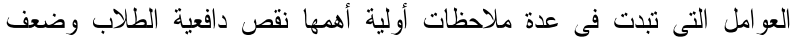

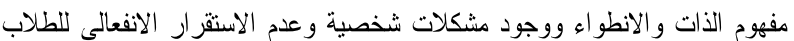

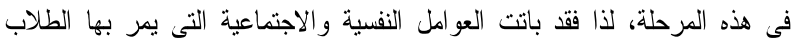

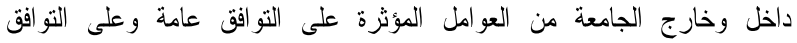

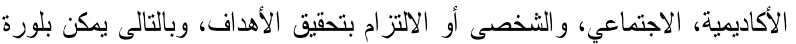

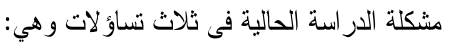

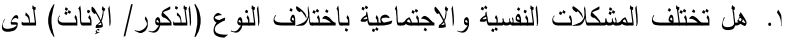
طلاب كلية التربية الأساسية بالكويت؟ له r. هل تختلف المشكلات النفسية والاجتماعية باختلاف الحالة الاجتماعية لاى طلاب الابلاب كلية التربية الأساسية بالكويت؟

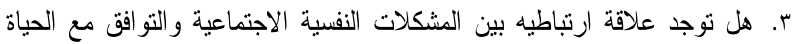

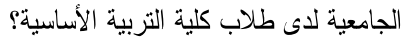

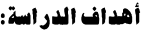

هدفت الدراسة الحالية إلى المقارنة بين الذكور والاناث على المشكلات النفسية والاجتماعية، وكذلك المقارنة بين الحالات الاجتماعية المختلفة (لم يسبق الزواج،

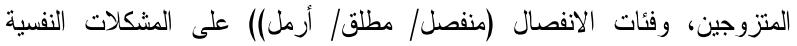

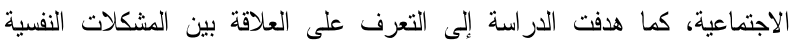

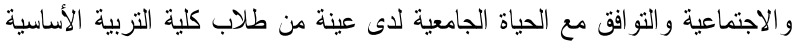

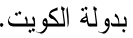

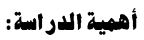

تبرز أهية هذه الدراسة في تتاولها لموضوع يعثبر ذا أهمية بالنسبة للطالب

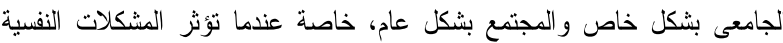

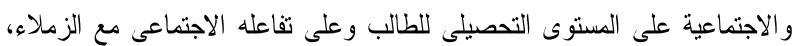

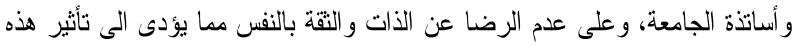

يعيش المجتمع الجامعي (فضلا عن أنه مجتمع أكاديمي) في بيئة اجتماعية تضم

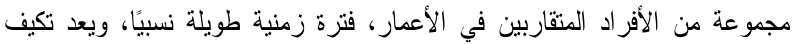

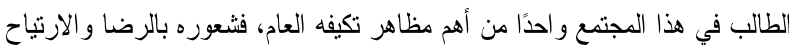
عن نوعية الحياة الجامعية يمكن أن ينعكس على إنتاجه وتحصيله.

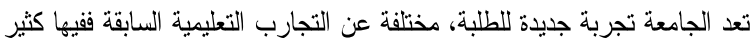

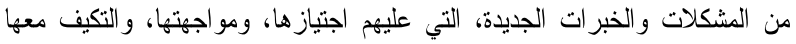
كالتعرف إلى أنظمة الجامعة ولو ائحها، واختيار التخصص و التكيف معه و الاختيار المهني والإعداد لمهنة المستقبل، وما يرتبط بذلك من اتخاذ قرارات ذات أهية ولئية بمستقبل الطلبة وحياتهم العلمية. كما يتعرض طلبة الجامعة إلى مشكلات تسهم في إعاقة تكيفهم وتحد من تحقيق لهان

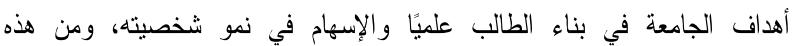

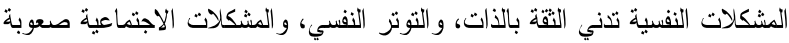

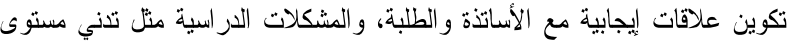

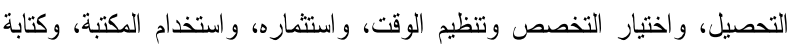

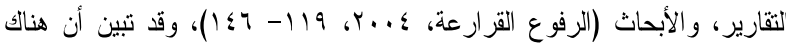

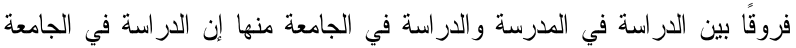

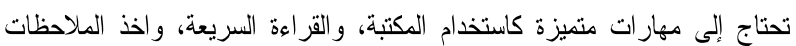

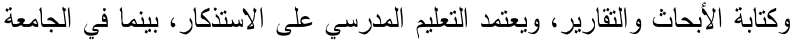
يعتمد على التحليل وغيره من مهارات التفكير، ويعتد الطالب على المدرس في التئي

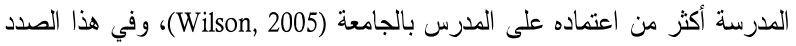
يضيف نيومان (New Man, 2005) يختلف الوسط الجامعي عن الوسط المدرسي لأنه

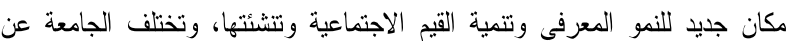

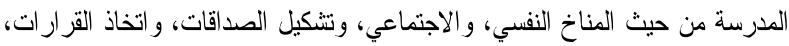

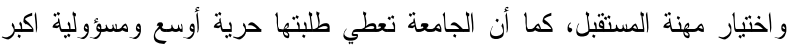
بعكس المدرسة.

و عادة ما يمثاز التكيف الإيجابي بمجموعة من المظاهر السلوكية مثل المحافظة على الشخصية المتكاملة وفهم الفرد لطبيعة سلوكه، وتغلبه على انفعالاته وفنشله،

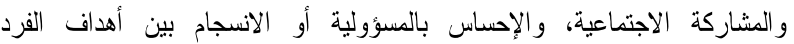

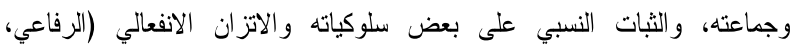

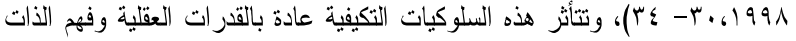
وجملة من العو امل الفسيولوجية والجسدية وحاجات الفرد الأولية وتغير المحيط البيئي وخاصة التغيرات السريعة والتي تتأثر بالتطور السريع لوسائل الاتصالات الحديثة ولئة ولئيل

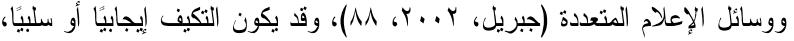

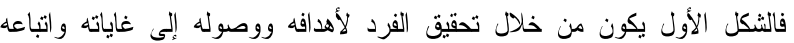

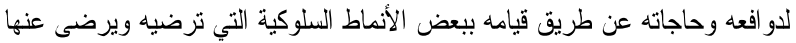
المجتمع. أما الثكل الثاني فهو التكيف السيئ وهو عجز الفرد عن إثباع حاجاته ودو افعه بطريقة مرضية لنفسه ويرضى عنها المجتمع، ويرجع العجز إلى أسباب

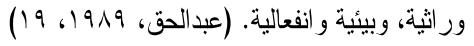
فضلا على تأثر التو افق العام بمدى قدرة الفرد على مواجهة مشكلات الحياة

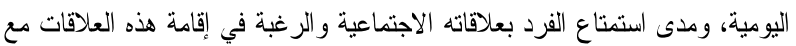

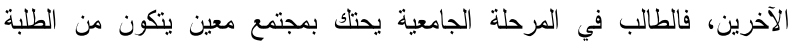

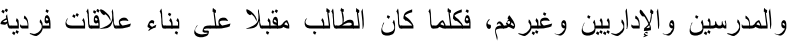

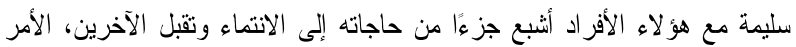
الذي يؤدي إلى ارتفاع مستوى التكيف لديه. ولذلك بات التعرف على المشكلات النفسية والاجتماعية التى يو اجهها طلاب

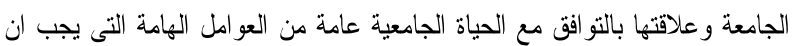
يهتم بها الباحثين نظر الأنها تفسر العديد من الظواهر النفسية والاجتماعية والبيئية 
العاطفي، و الالتز ام بتحقيق الأهداف.

الإطار النظرى للدراسة:

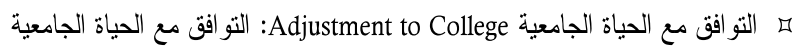

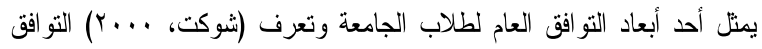

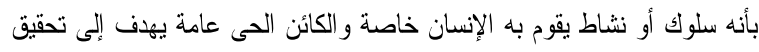

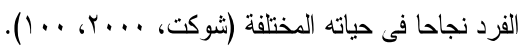

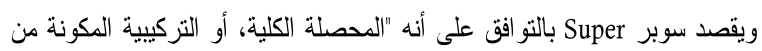

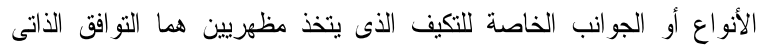
و الذى ينعلق بالتنظيم النفسى الذاتى للفرد و التو افق الاجتماعي، ويعنى بالعلاقات

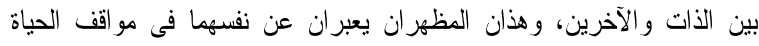

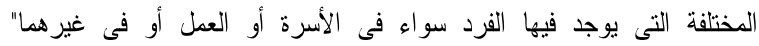

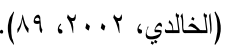

وأول تعريف للتو افق العام يقترب إلى تحديد مفهوم التوافق مع الحياة الجامعية وهو تعريف أركوفت (Arkoff, 1986) و الذى يشير إلى مفهوم التو افق العام بأنه

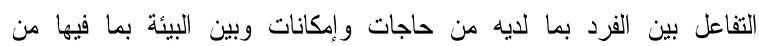

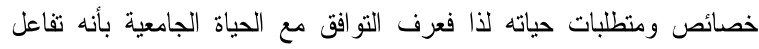

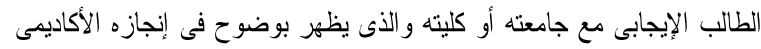

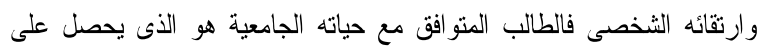

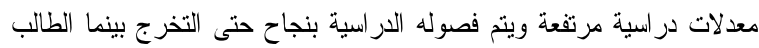

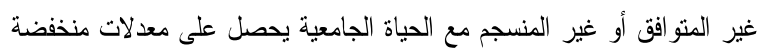

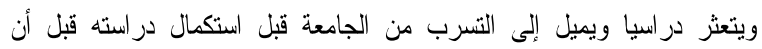

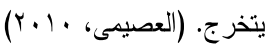
ويرى كل من بوكير وسيرك (Baker\& Siryk, 1999) التو افق مع الحياة الجامعية

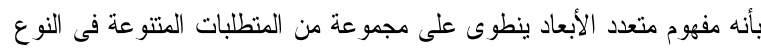

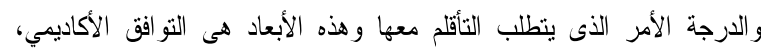

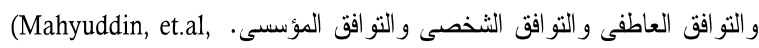
2010, 497)

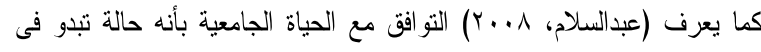

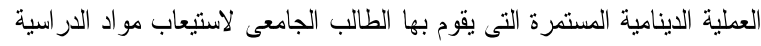

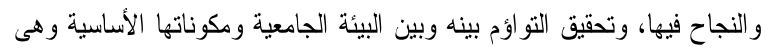

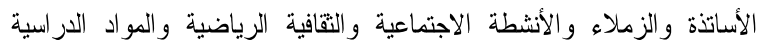

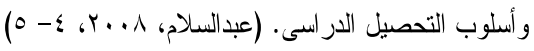

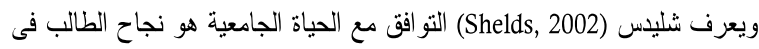

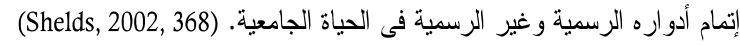

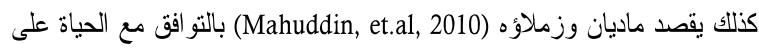
أنه كل الجهود التى يقوم به الطالب للتغلب على مختلف الضغوط و الصعاب التى مانى

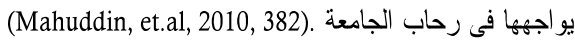
علاوة على ذلك يذكر (عبدالسلام، ^. ..ب) بأن هناك أبعاداً للتو افق مع الحياة

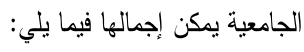

1. التو افق الأكاديمي: وهو قدرة الطالب على الوصول إلى إلى حالة الرضا النفسى

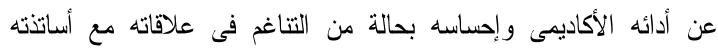
وزملائه فى الدراسة ومع البيئة الجامعية.

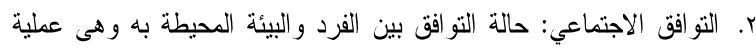

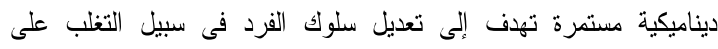

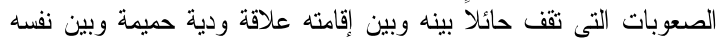

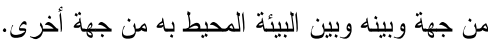

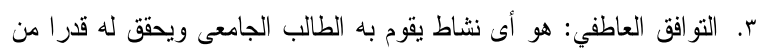

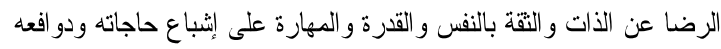

المشكلات على التوافق مع الحياة الجامعية، هذا فضلاً عن انتقال الطالب من بيئة

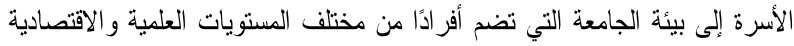

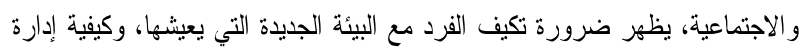

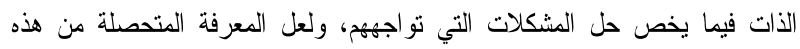

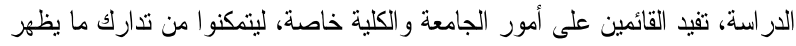

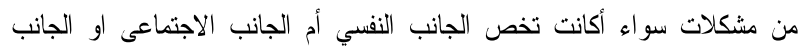

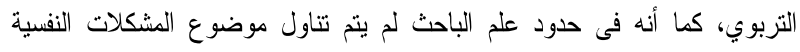

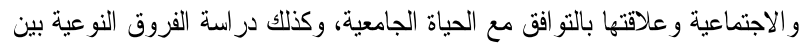

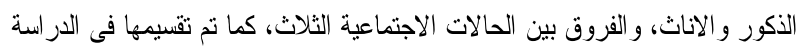
الحالية، فى المشكلات النفسية و الاجتماعية لدى طلبة الجامعة.

مصطات الدر اسلة:

I المشكلات النفسية الاجتماعية: وهى تمثل مجموعة المواقف والصعوبات

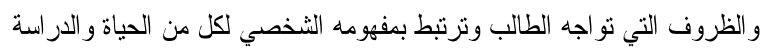
الجامعية وبالعلاقات وبخاصة فيما بينه وبين الزملاء داخل الكلية وبينه وبين

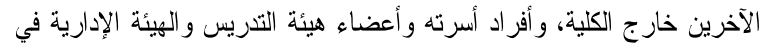

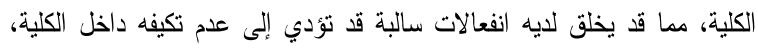

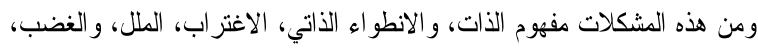
و المشكلات الشخصية، وعدم الاستقر ار الانفعالى.

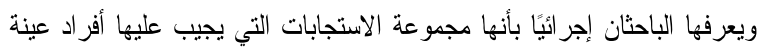
الدر اسة على فقر ات مقياس المشكلات النفسية الاجتماعية.

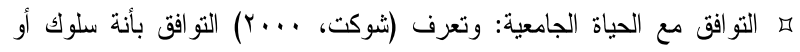

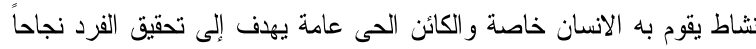

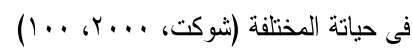
عملية دينامية مستمرة تتتاول السلوك و البيئة (الطبيعية والاجتماعية) بالتغير

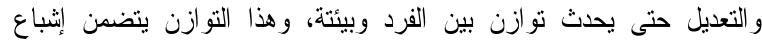

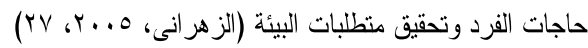
وتعرف هذه الأبعاد كما جاءت فى المقياس كمايلي:

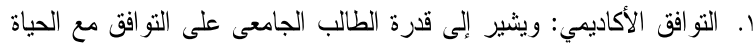

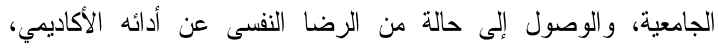

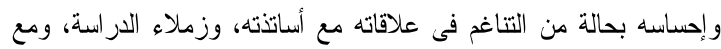
البيئة الجامعية. r. التو افق الاجتماعي: وتقيس حالة التو افق بين الفرد و البيئة المحيطة به، وهى

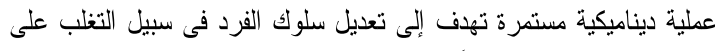

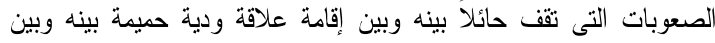
نفسه من جهة، وبينه وبين البيئة المحيطة به من جهة أخرى. لئه

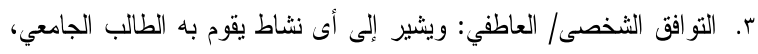

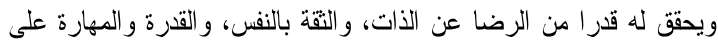

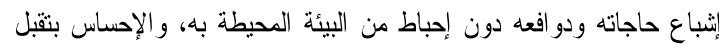

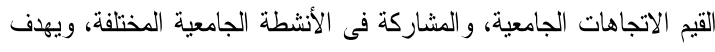

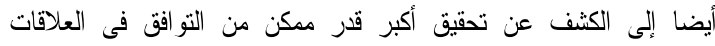

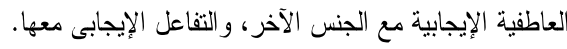

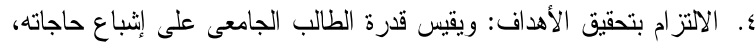

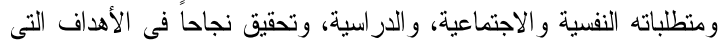

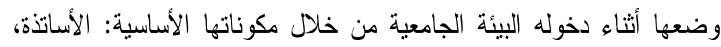

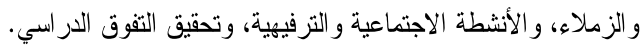

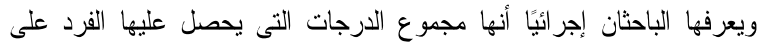

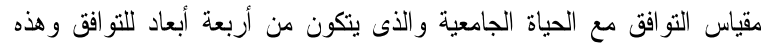

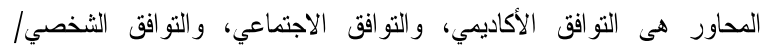


وعلاقاته بهم، ويعد الاعتبار الإيجابي للذات حاجة يسعى إليها الفرد، فمن

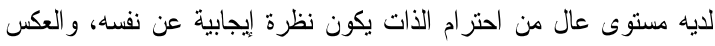

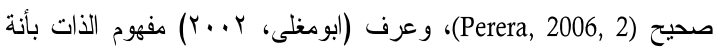
تكوين نظرى معرفى منظم موحد ومتعلم لمدركات الثعورية والتعميمات

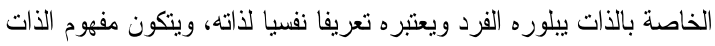
من أفكار الفرد الذاتية المتسقة المحدة الأبعاد عن العناصر المختلفة لكينونته لفئه

الداخلية و الخارجية، وتشمل هذه العناصر :

أ. المدركات و التصورات التى تحدد خصائص الذات كما تتعكس اجر ائياً فى وصف الفرد لذاته كما يتصور ها هو (الذات المدركة).

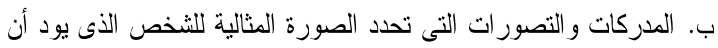
يكون (الذات المثالية). ج. المدركات و التصورات التى تحدد الصورة التى يعتقد أن الآخرين

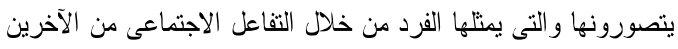

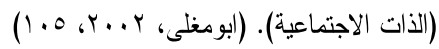

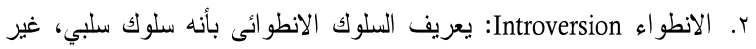

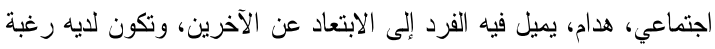

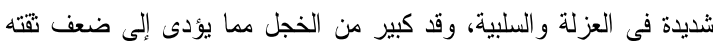

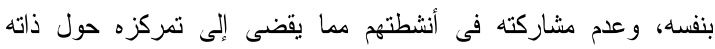

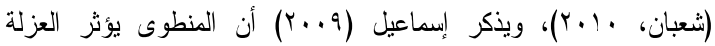

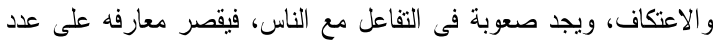

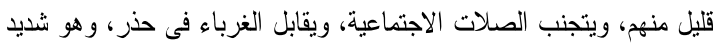

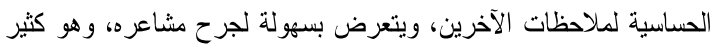

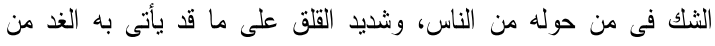

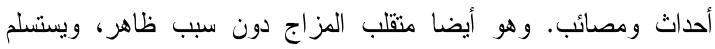
لأحلام اليقظة. وهو كثير الندم والتحسر على ما فات، ولا يعبر مظهره

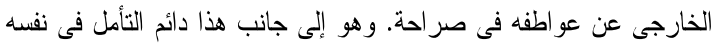

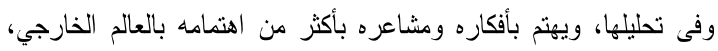

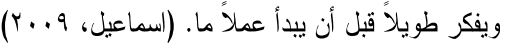
r. الاغتراب- الملل Alienation- Boredom: أنه شعور الفرد بالانفصال عن هن الآخرين أو عن الذات أو كليهما (Paik\& Michael, 2002, 23)، او هو مالفالفيال

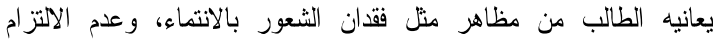

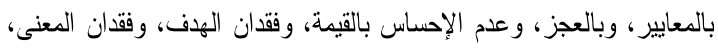
و التمركز حول الذات.

مع تعرض المجتمع بأكمله إلى "مظاهر تكيف مضطربة نتيجة للاحباطات

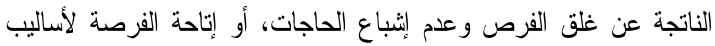
إثباع وهية للرغبات المحبطة، فإن الأمر يجعل من يلجئون إلى الأساليب

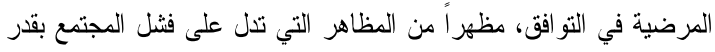

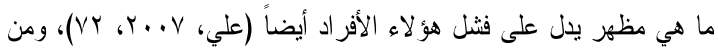

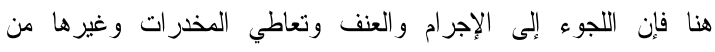

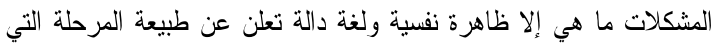

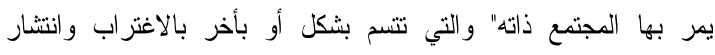

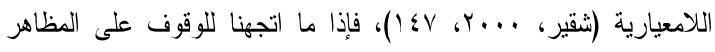

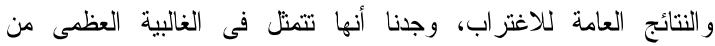

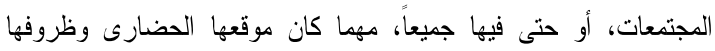

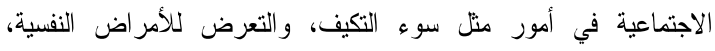

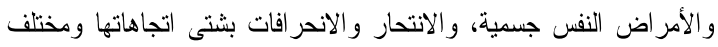
صورها، وخاصة ما تعلق منها بالخروج على النظام و التمرد بكل أثكاله

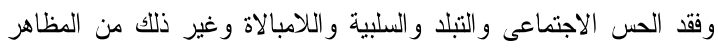

دون إحباط من البيئة المحيطة فهو الإحساس بتقبل القيم و الاتجاهات الجامعية

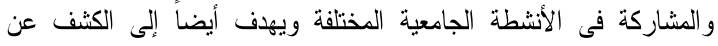

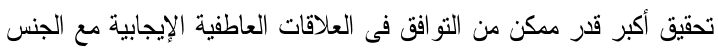
الآخر و الثفاعل الإيجابى معها.

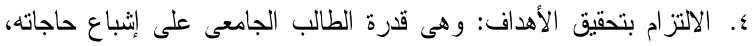

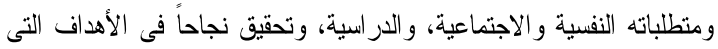

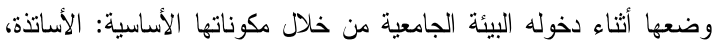

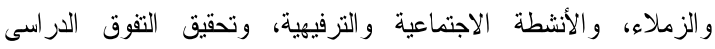

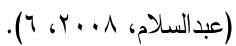

وعموماً يجدر الإشارة إلى أن هناك مجموعة من المؤشرات التى يرى العلماء

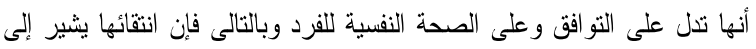

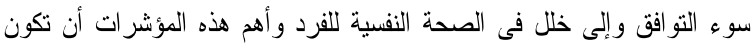
نظرة الفرد للحياة و اقعية، وأن تكون طموحات الفرد بمستوى قدر اته و إمكانياته،

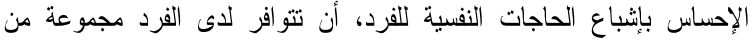

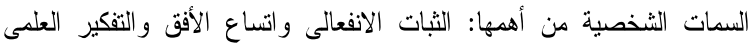

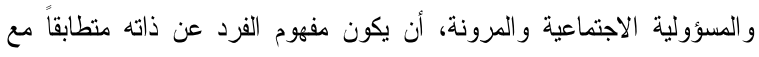

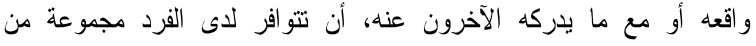

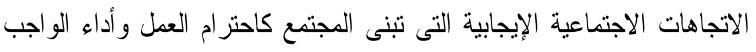

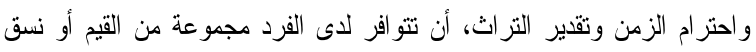

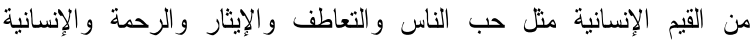

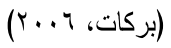

口 المشكلات النفسية والاجتماعية: يعرن تشن (Chen, 2016) المشكلة أنها شيء

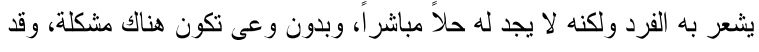

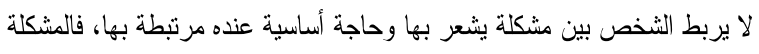

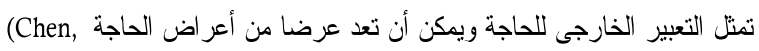

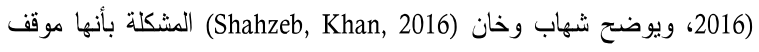
جديد يكون بمثابة عقبة تعوق إرضاء حاجات الفرد ورغباته، ولا يكفى لحله

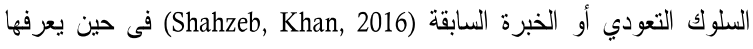

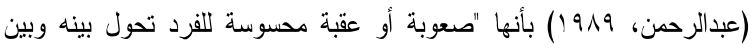

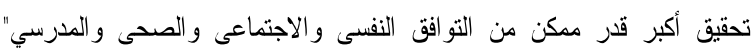

(عبدالرحمن، 1919 19 10 (10).

وينتهى الباحث بالتعريف التالى للمشكلة بأنها صعوبة أو عائق تعيق سير الطالب الأب

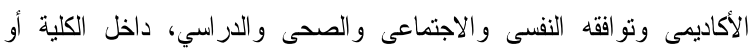
خارجها مسببة له الضيق و الألم. ومن ناحية أخرى قسم أريكسون المشكلات التى يحتاج فيها الطلاب للمساعدة إلى في

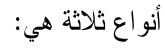
1. التعرف على معلومات معينة كالتعرف على المهن المختلفة و الفرص فيها، أو أو الفئ الجامعات و الكليات و التخصصات بما يتتاسب مع مؤهلات الأفر اد.

r. المساعدة على التكيف فى ظروف يعجز الفرد على تغييرها.

r. المساعدة على النمو و النظور (Uguak, Elias, Uhi\& Suandi, 2006) وفى هذه الارسة سيتتاول الباحث دراسة مشكلات محددة وهى بعض المض المشكلات

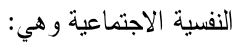
1. مفهوم الذات Self- Concept: و هو المجموع الكلى لادر اكات الفرد، وهو

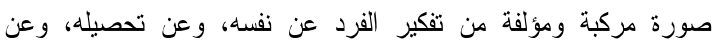

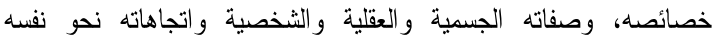

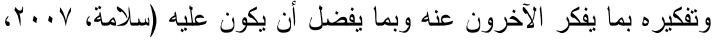

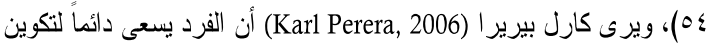
صورة مثالية عن ذاته من قبله ومن قبل الآخرين، وذللك من خلال تصرفاته 


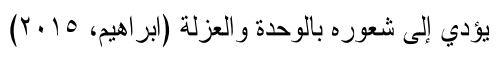

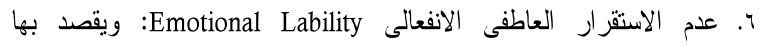
التغيرات المزاجية التى تتم عن عدم الاستقرار الانفعالى وعرضته لذللك،

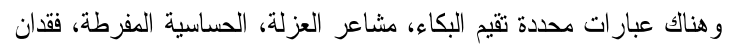
الحالة المز اجية، والغضب نحو الآخرين. وقد أظهرت الإناث فى عينة التقنين

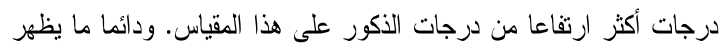

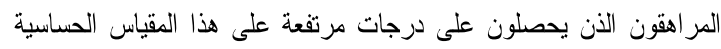

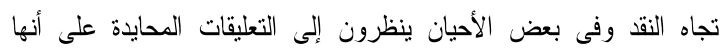

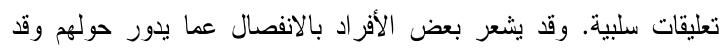

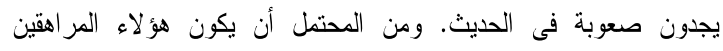

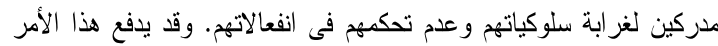

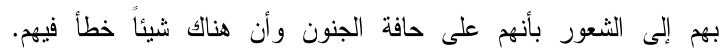

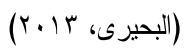

الدر اسات السابقة:

ا. دراسة ستيفانى (Stephanie, S, 2016) هدفت الدراسة الحالية إلى التعرف على

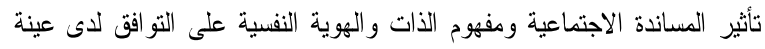

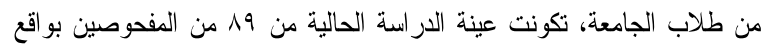
(أنثى، Y VV)

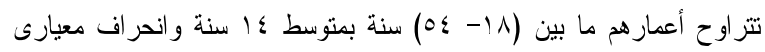

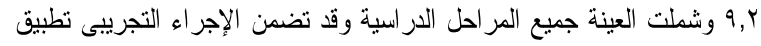

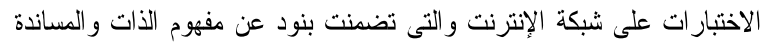

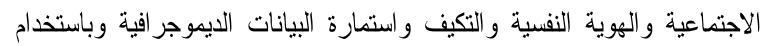

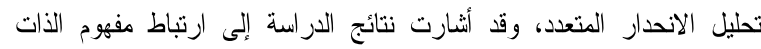

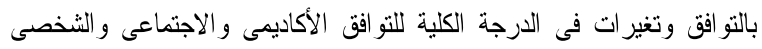

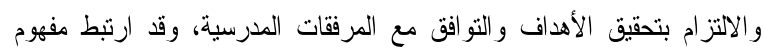

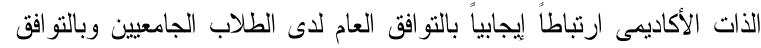

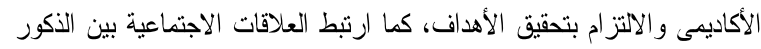

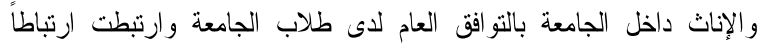

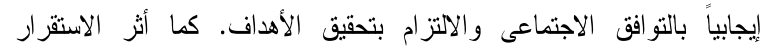

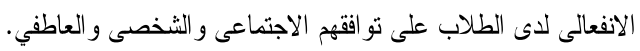

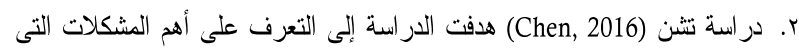

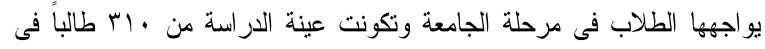

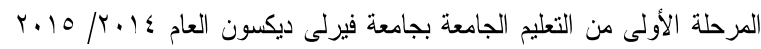

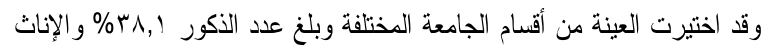

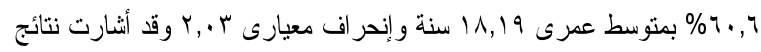

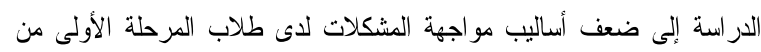

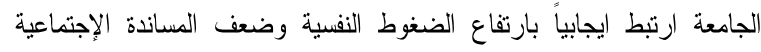

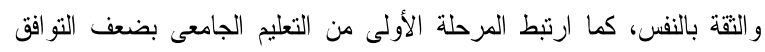

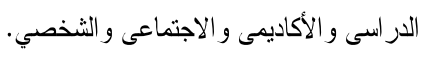

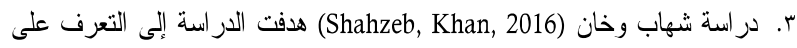

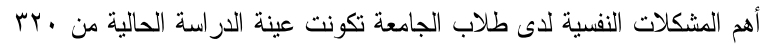

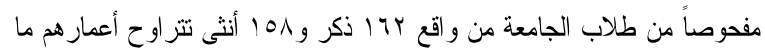

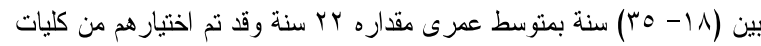

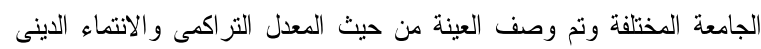

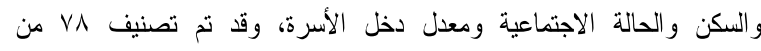

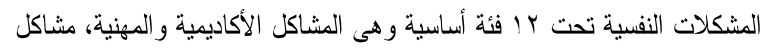

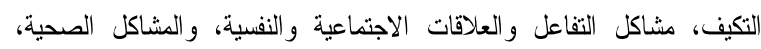

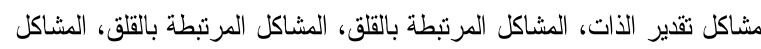

اللاسوية التي يأباها أي مجتمع (بدر، 1994، 94)، وهناك عو امل متعددة

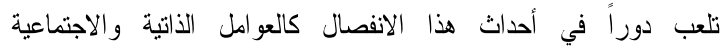
والاقتصادية، ومع ازدياد أهية جيل الشباب تزداد أيضاً تقافته وتعليمه

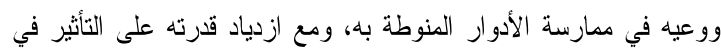

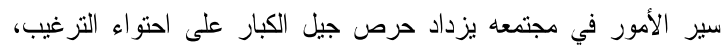

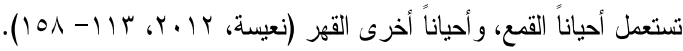

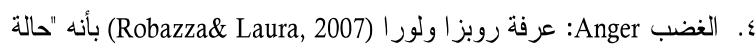

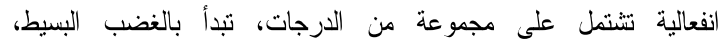
والاستثارة، والضيق ثم تتتهي بالغضب الثديد المتمثل في العنف، ويتسم

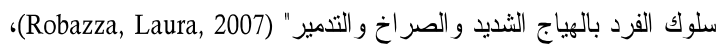

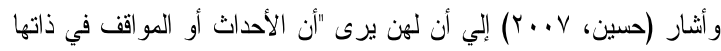

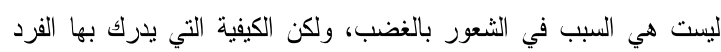

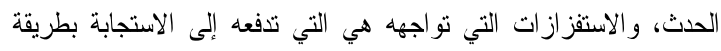

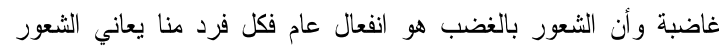

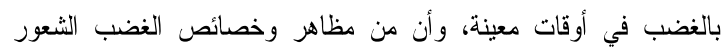

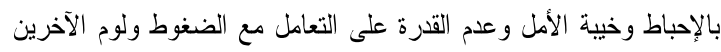

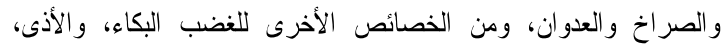

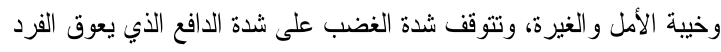

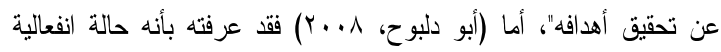

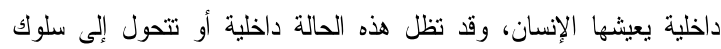

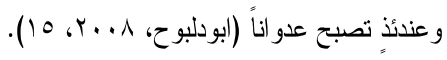

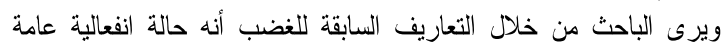

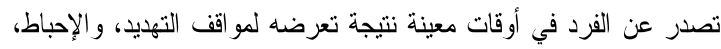

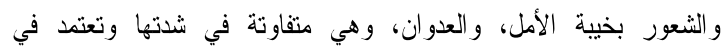

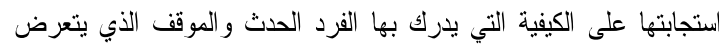

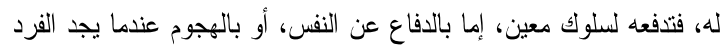

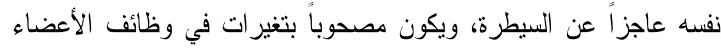

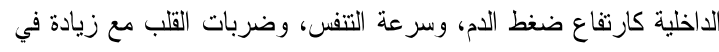

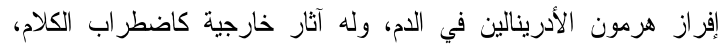

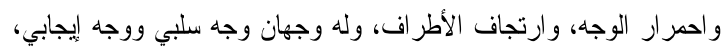

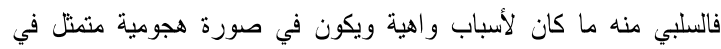

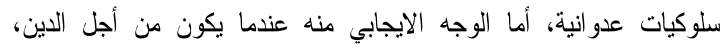

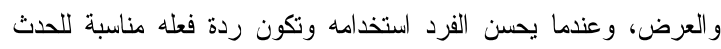
الذي آثنار غضبه.

ه. المشكلات الشخصية Interpersonal Problem: وتدخل ضمن إطار المشاكل النفسية والاجتماعية حيث تنحصر في: أ. الإحساس بالفر اغ نتيجة عدم إحالة الطالب على المكتبات، أو هذا يعزى في

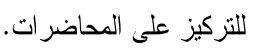
ب. عدم الإيمان بالرسالة التي يعد من اجلها، و النظر إلى الكلية على أنها مصنع الثهادات للحصول على الوظيفة.

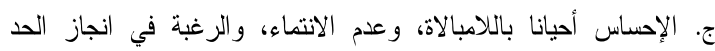

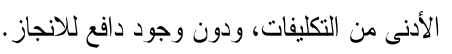

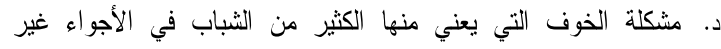

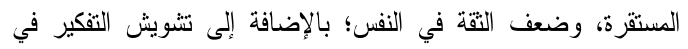

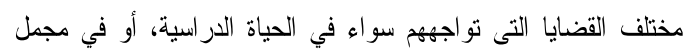
الحياة التي يعيشها. ه. عدم قبول الطالب للحياة الاجتماعية بما فيها من بناء صداقات وعلاقات

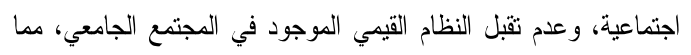


ومكان وجود الجامعة وتغيير التخصص كما هدفت معرفة الفروق فى واقع

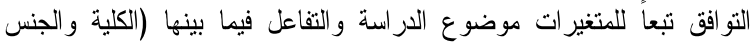

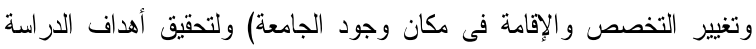

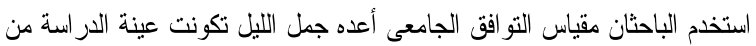
(ن

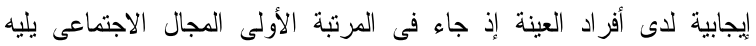

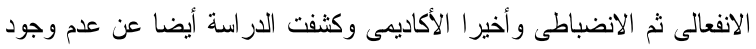

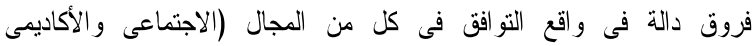

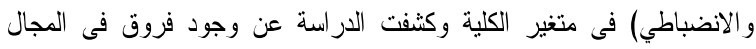

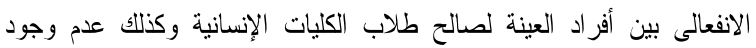
فروق بين الذكور والإناث من أفراد العينة فى المجالين (الاجتماعى والإنفعالي)

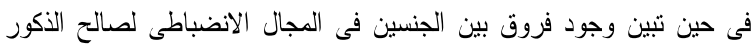

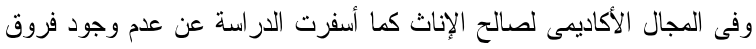
بين أفر اد العينة فى المجال الانضباطى طبقا لمتغير التخصص بلينما تبين وجود

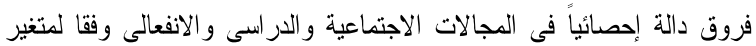

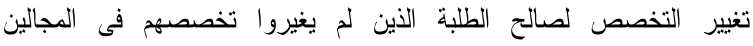

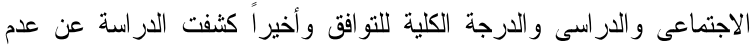
وجود فروق فى المجالين الانضباطى و الانفعالى بين الطلاب طبقا لمتغير الإقامة الإنة

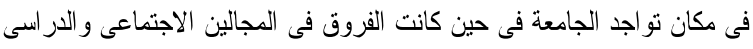
لصالح الطلبة يقيمون فى مكان بعيد عن وجود الجامعة.

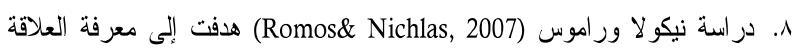
بين التوافق مع الحياة الجامعية والفاعلية الذاتية لاى طلبة الجامعة أجريت

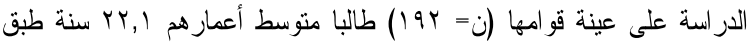

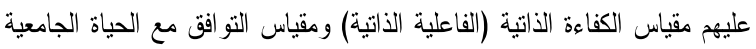

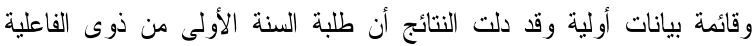

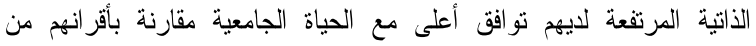

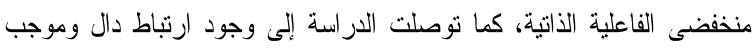

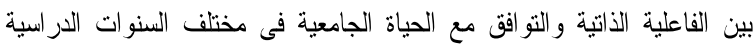
الجامعية. 9. دراسة ولسن وزملاؤه (Wilson, et.al, 2007) هدفت إلى معرفة دور كل من

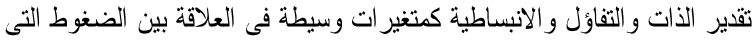

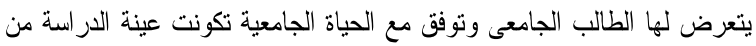

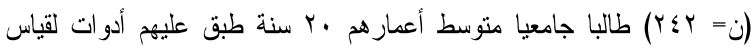

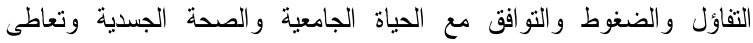

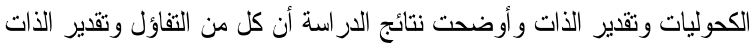

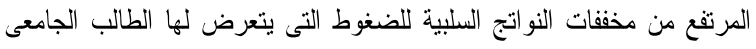

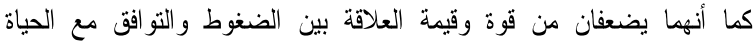

الجامعية و أنهما أيضاً ينبئان بالتو افق الجيد مع الحئة الحياة الجامعية. 1. در اسة أوغو اكك و إليس و أولى وسوندى (Uguak, Elias, Uhi\& Suandi, 2006) هدفت الدراسة إلى إيجاد تفسير للتو افق الدراسى والحالة النفسية لاى الطلاب

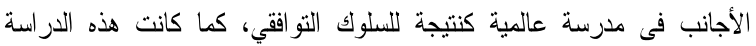

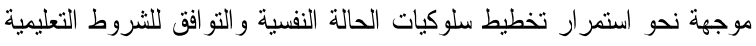

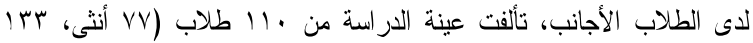

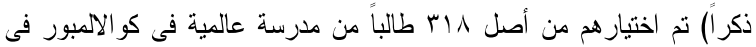

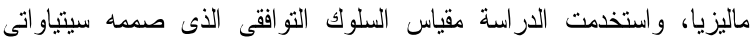
Setiawati

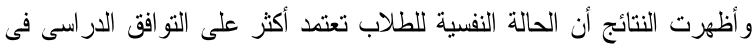

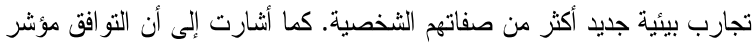

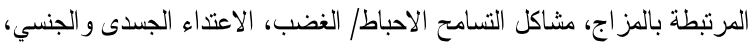

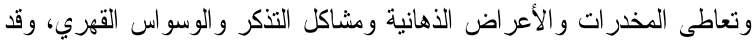

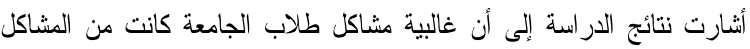

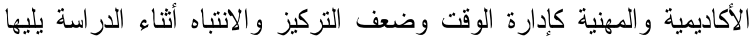
مشاكل تقدير الذات كالثعور بالنقص وعدم الثقة ثم المشاكل المتعلقة بالمزاج

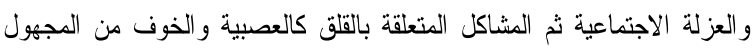
ومن الفشل ومن المستقبل. ع. در اسة ستوكلوز (Stoklose, M, 2015) هدفت الدراسة إلى التعرف على العلاقة

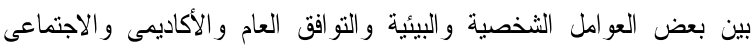

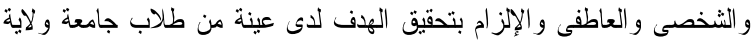

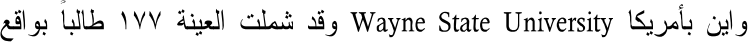

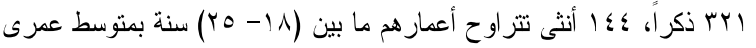

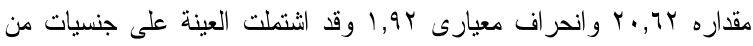

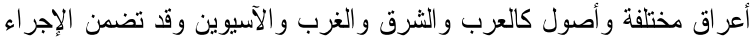

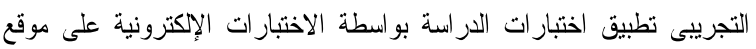

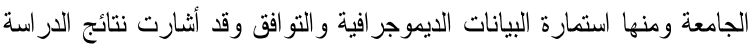

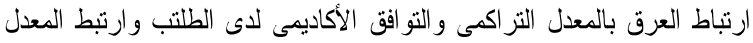

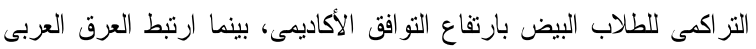

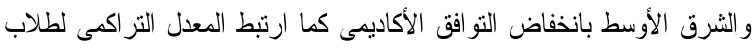

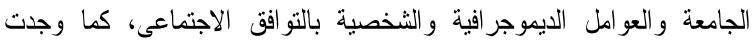

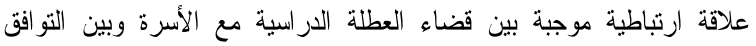

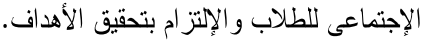

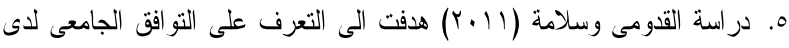

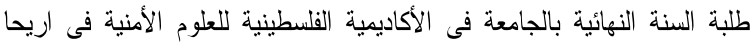

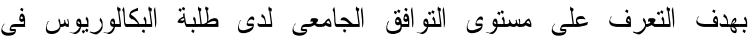

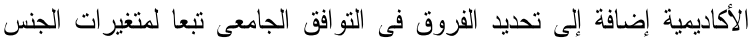

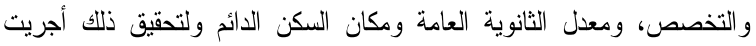
الدراسة على جميع طلبة البكالوريوس فى الأكاديمية فى تخصص ولى علم النفس ولنس

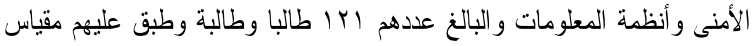

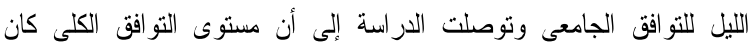

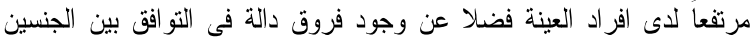

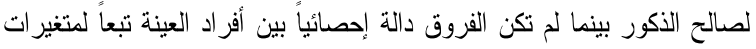
التخصص ومعدل الثانوية العامة ومكان السكن الدائم.

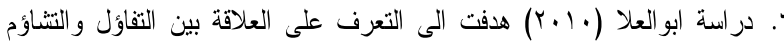

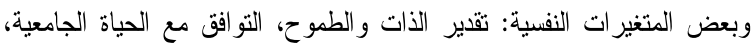

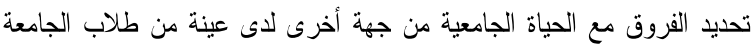

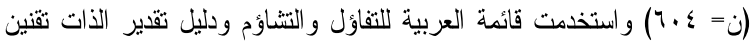
مجدى الدسوقى ومقياس مستوى الطموح (محد عبدالتواب وسيد عبدالعظيم)

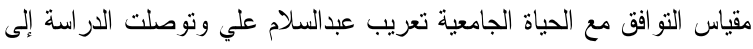
وجود علاقة ارتباطية موجبة ودالة بين التوافق مع الحياة الجامعية وكل من التفاؤل وتثدير الذات و الطموح وكثفت عن وجود ارتباط سالب ودالة إحصائياً

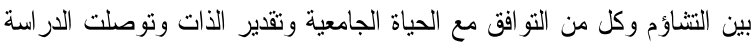

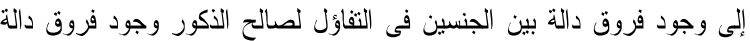

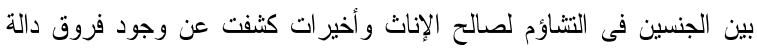
بين الجنسين فى كل من تقدير الذات والتوافق مع الحياة الجامعية والطموح

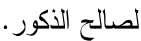

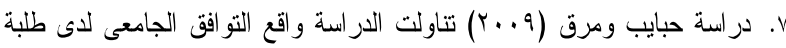

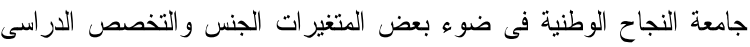




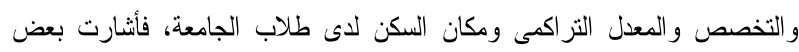

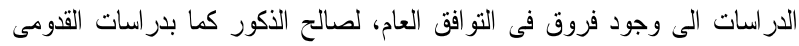

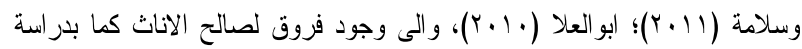

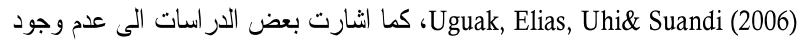

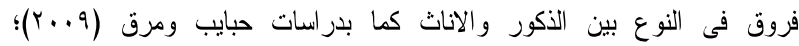

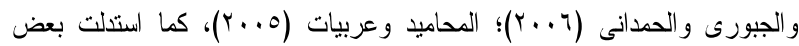

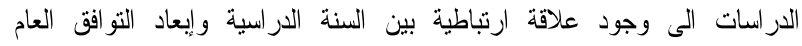

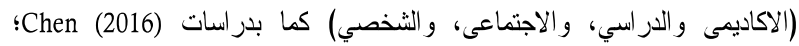

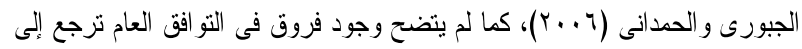

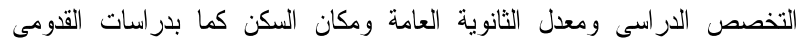

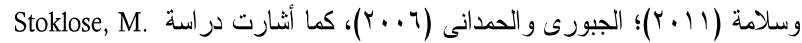
(2015) إلى وجود علاقة ارتباطيه بين التو افق العام للطلاب و الثقافة العامة السائدة

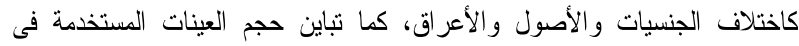

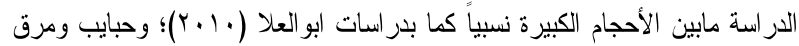

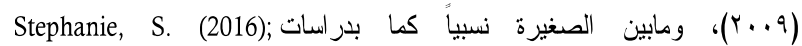
.Mehdizadeh, N.\& Scott, G. (2005) كما يلاحظ أن تلك الدراسات كثفت عن تضارب نسبى فى بعض النتائج التى توصلت إليها، وقد يرجع ذلك إلى استخدام تلك البحوث لعينات متفاوتة فى جنسها،

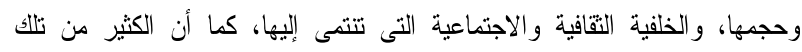
البحوث أجريت على عينات من مجتمعات ذات طبيعة مختلفة عن البيئة و التقافة

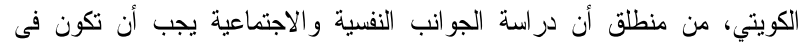

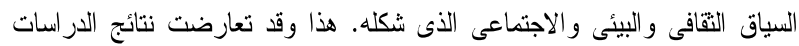

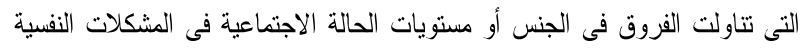

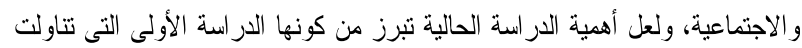
الفروق بين بعض المتغيرات الديموجر افية والعلاقة بين المشكلات النفسية و الاجتماعية و التو افق مع الحياة الجامعية.

فروض الدراسة:

1. تختلف المشكلات النفسية و الاجتماعية باختلات النوع (الذكور / الإناث). r. r. تختلف المشكلات النفسية والاجتماعية باختلاف الحالة الاجتماعية.

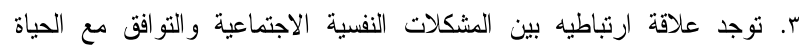
الجامعية لدى طلاب كلية التربية الأساسية.

منهج الدراسة: تعد هذه الار اسة من الار اسات الوصفية التحليلية لأنها تهدف إلى رصد وتوصيف

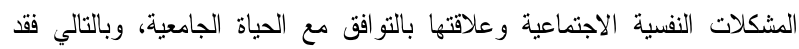

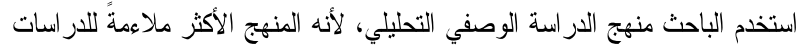

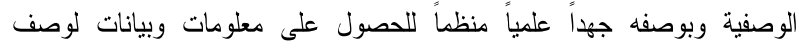

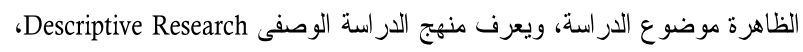
بالمنهج الذى يدرس المتغير ات كما هي موجودة في حالاتها الطبيعية، لتحديد العلاقات

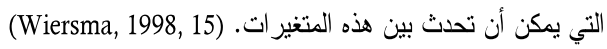

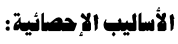

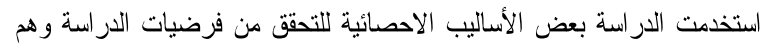

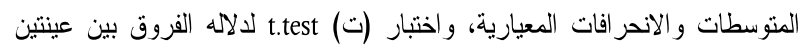

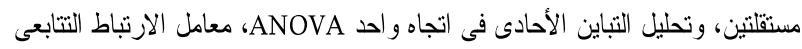

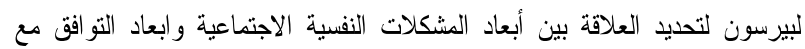

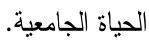

عينة الدراسة:

تكونت عينة الدراسة الأولية من م؛ي مفحوصاً من طلاب المرحلة الجامعية

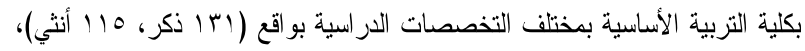

مهز للحالة النفسية للطلاب، وأشارت الدراسة إلى أن التوافق الدراسى والحالة النفسية لدى الإناث تكون أعلى من الذكور فى بيئة تعليمية جديدة.

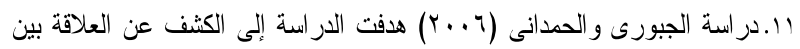

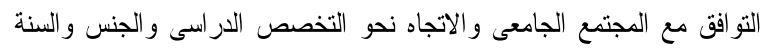

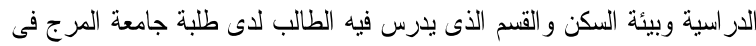

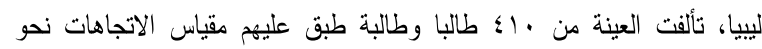
التخصص ومقياس التو افق مع المجتمع الجامعي، وتوصلت الدر اسة إلى أن العينة

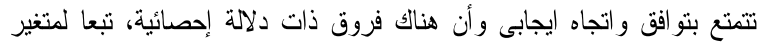

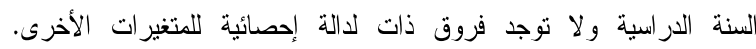

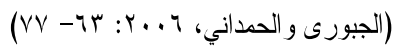

ץ.ا.دراسة مهدى زاده وسكوت (Mehdizadeh, N.\& Scott, G, 2005) هدفت الدراسة إلى اختبار مجموعة المتغيرات التى تبدو أنها تؤثر فى عملية التو افق

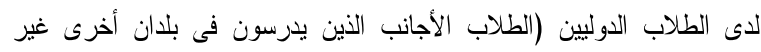

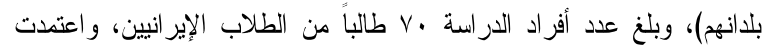

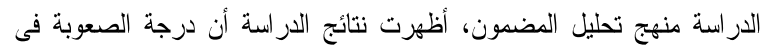

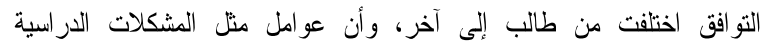
و الاجتماعية النفسية والثقافية يمكن أن تؤثر فى تو افق الطلاب فى اسكتلندا، كما

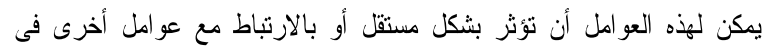
تو افق الطالب مع بيئة جديدة.

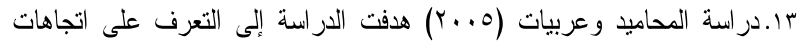
طلبة جامعة مؤتة نحو الإرشاد الأكاديمى وعلاقته بتكيفه الدراسى الستى الستاداً

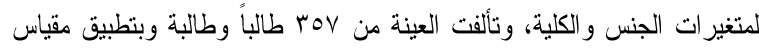

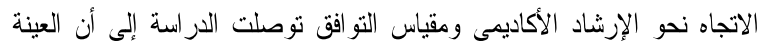

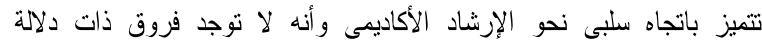

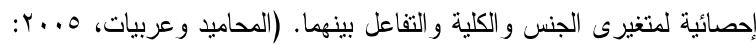

$(179-10)$

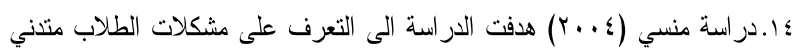

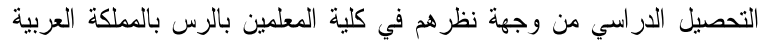

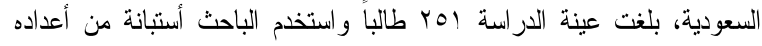

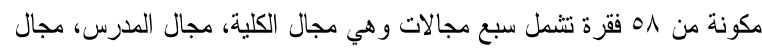

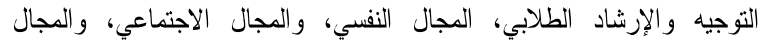

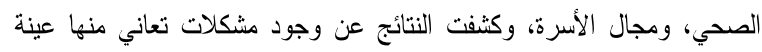

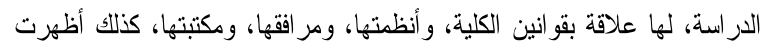

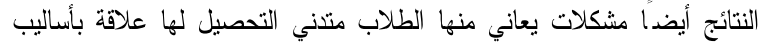

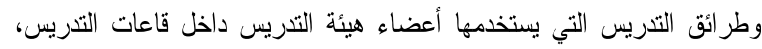

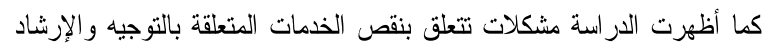

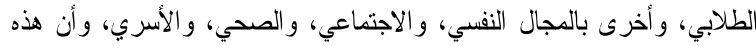
المشكلات مختلفة في حدتها باختلاف مستوى تندي التحصيل.

تعقيب على الدر اسات السابقة:

نلاحظ أن الدراسات السابقة قد تنوعت حسب الهدف منها فمنها ماهدف الى كانى التعرن على العلاقة بين المتغيرات الثخصية و النفسية والبيئية و التقافية كالمساندة

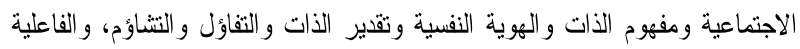
الذاتية، والحالة النفسية وبين التوافق العام لاى طلاب الجامعة كما بدراسات

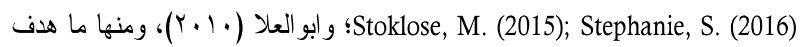
إلى التعرف على المشكلات النفسية والاجنماعية التى يواجهها الطلاب بالمرحلة

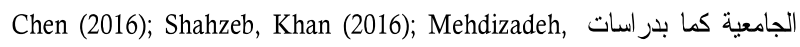
ودر اسة منسي (ع.\&Scott, G. (2005)

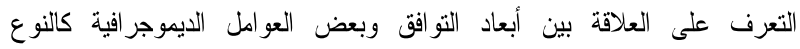


مثلت الحالة الاجتماعية الثانية وهى المتزوج نسبة ب,؟؟\%، فى حين مثلت انماط

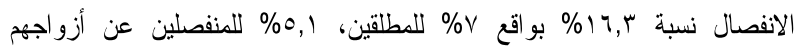

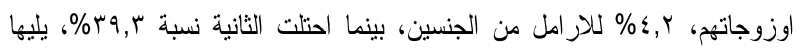

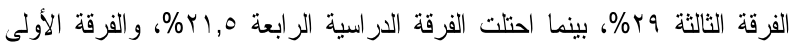

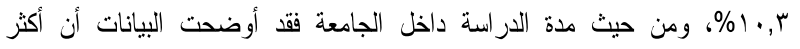

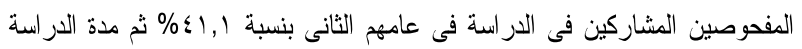

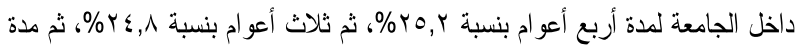

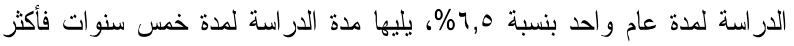

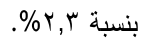

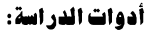

طبقت الدر اسة الحالية الأدوات التالية لقياس متغير ات الدر اسة وهي: ه مقياس التو افق مع الحياة الجامعية Adjustment to College Scale (ATCS) أعداد روبرت بيكر، بو هدن سير الك (Robert Baker\& Bohadon Siryk, 1984)

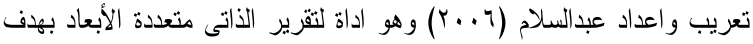

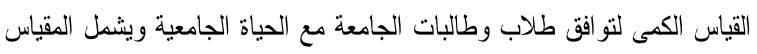

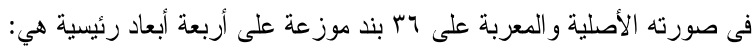

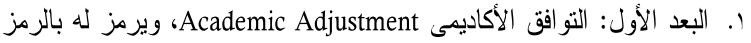

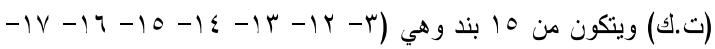

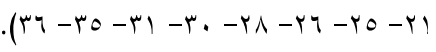

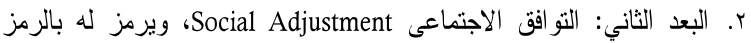

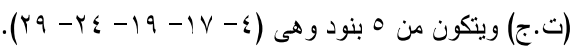

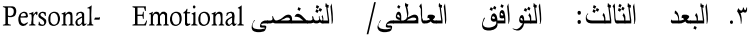
Adjustment

$$
\text { . } r V-r r-r .-1 \Lambda-q-\Lambda-7
$$

Attachment \. Gool Commitment البعد الر ابع: الالتز ام بتحقيق الأهداف

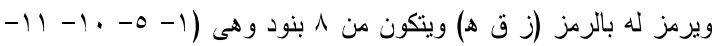

. (r)

الخصائص السيكومترية للمقياس: صدق وثبات المقياس: 1. ثبات المقياس: تم حساب معامل ثبات "مقياس التو افق مع الحياة الجامعية"

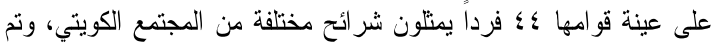

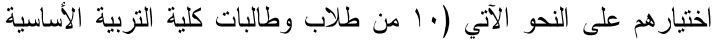

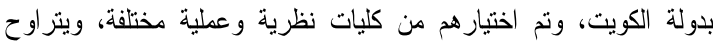

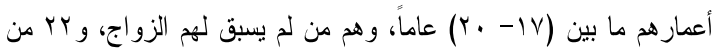

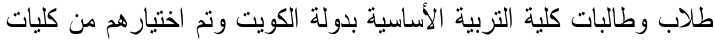

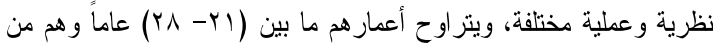

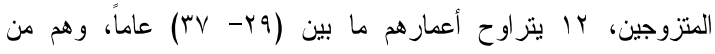
المنفصلين و المطلقين والأرامل، ومن محافظات الكويث المختلفة). وتم حساب معامل ثبات المقياس بطريقتى أعادة الاختبار والتجزئة النصفية ولأنية

\begin{tabular}{|c|c|c|c|}
\hline \multicolumn{2}{|c|}{ التجزئة النصفية } & \multirow{2}{*}{ أعادة النطبيق } & \multirow{2}{*}{ الأبعاد } \\
\hline جتمان & سبيرمان- بر اون & & \\
\hline.,$V_{0}$ & $\cdot, V Y$ & $\cdot, \mathrm{V} \leqslant$ & التو افق الأكاديمى (ت. ك) \\
\hline$\cdot, \mathrm{Vi}$ & $\cdot, \mathrm{V} \leqslant$ & $\cdot, \mathrm{V}$ & الثو افق الاجتماعى (ت. ج) \\
\hline 西 & $\cdot, 10$ & דוג & التو افق العاطفى- الثخصي (تع/ش) \\
\hline$\cdot, \wedge \varepsilon$ & $\cdot, \wedge i$ & $\cdot, \mathrm{AV}$ & الالتز ام بتحقيق الأهداف (ز ق ه) \\
\hline
\end{tabular}

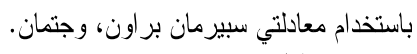

جدول (r) يوضح معاملات ثبات مقياس التو افق مع الحياة الجامعية

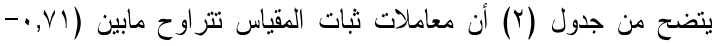
AV

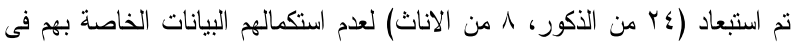

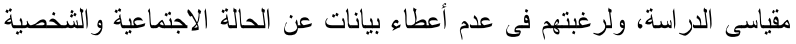

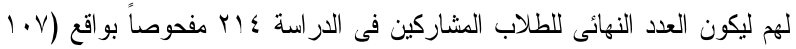

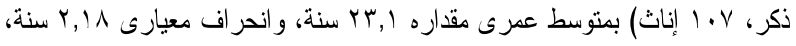

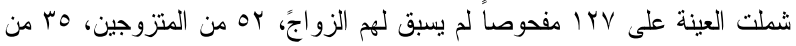

\begin{tabular}{|c|c|c|c|}
\hline النسبة & التكر ار & الحالات & المتغير \\
\hline$\% \circ$. & $1 . v$ & ذكر & \multirow{3}{*}{ النوع } \\
\hline$\%$ & $1 . V$ & انثي & \\
\hline$\% 1 \ldots$ & YIS & المجموع & \\
\hline$\% 17,7$ & ro & العاصمة & \multirow{7}{*}{ المحافظات } \\
\hline$\% 11, \varepsilon$ & $r \leq$ & حولي & \\
\hline$\% Y \leqslant, Y$ & 01 & الجهر اء & \\
\hline$\%$ Yr,Y & $\varepsilon \wedge$ & الفرو انية & \\
\hline$\% 10, r$ & ro & الأحمدي & \\
\hline$\% 1$. & Y & مبارك الكبير & \\
\hline$\% 1 \ldots$ & $Y I \leq$ & المجموع & \\
\hline$\%\{\cdot, 1$ & 10 & $r \cdot-I V$ & \multirow{7}{*}{ الفئات العمرية } \\
\hline$\% \leqslant r, q$ & $9 \pi$ & $r \leq-r)$ & \\
\hline$\% \curlyvee, \uparrow$ & $1 \leqslant$ & $r_{\Lambda}-r_{0}$ & \\
\hline$\% \varepsilon, Y$ & 9 & $r r-r q$ & \\
\hline$\% r, \Lambda$ & $i$ & מיז- & \\
\hline$\%$ \%, & v & 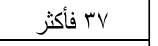 & \\
\hline$\% 1 \ldots$ & $Y I \leq$ & المجموع & \\
\hline$\% \circ 9, r$ & ITV & لم يسبق الزواج & \multirow{6}{*}{ الحالة الاجتماعية } \\
\hline$\% r \varepsilon, r$ & or & متزوج & \\
\hline$\% 0,1$ & 11 & منفصل & \\
\hline$\% v$ & 10 & مطلق & \\
\hline$\% \varepsilon, r$ & 9 & أرمل & \\
\hline$\% 1 \ldots$ & YIS & المجموع & \\
\hline$\% 1 \cdot, r$ & rr & الأولي & \multirow{5}{*}{ السنة الدر اسية } \\
\hline$\% \sqcap q, r$ & $\Lambda \leqslant$ & الثانية & \\
\hline$\%$ \% & $\pi$ & الثالثة & \\
\hline$\% r l, 0$ & $\leq 1$ & الر ابعة & \\
\hline$\% 1 \ldots$ & YIE & المجموع & \\
\hline$\% \uparrow, 0$ & $1 \leqslant$ & عام & \multirow{6}{*}{ مدة الدر اسة داخل الجامعية } \\
\hline$\%\{1,1$ & 11 & عامين & \\
\hline$\% r \leqslant, \Lambda$ & or & ثلاث أعوام & \\
\hline$\%$ Yo,r & $0 \leqslant$ & أربع أعوام & \\
\hline$\% r, r$ & . & خمس أعوام فأكثر & \\
\hline$\% 1 \ldots$ & YIS & المجموع & \\
\hline
\end{tabular}

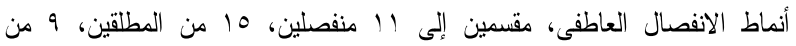
الأر امل، ويوضح جدول ( النفاط ) وصف عينة الدراسة. جلول (1) يوضح خصائص عينة الدر اسة الأساسية

يتضح من جدول (1) الخاص بوصف العينة الأساسية للار اسة الحالية و المكونة

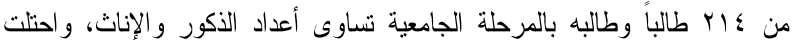

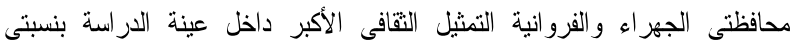

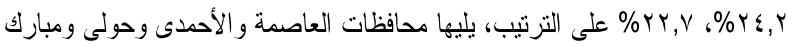

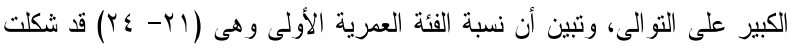

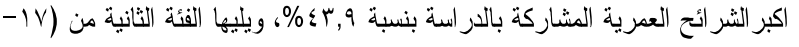

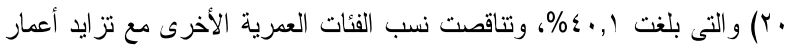

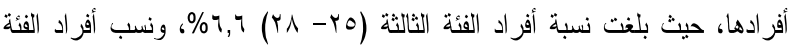

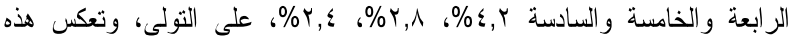

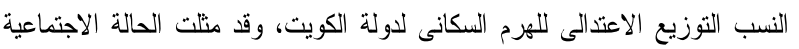

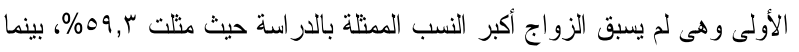




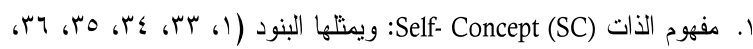

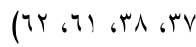

r. Introversion (IN) : الانطواء

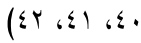

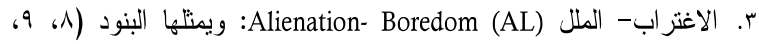

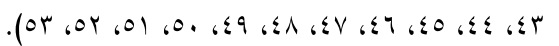

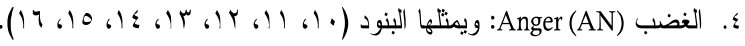

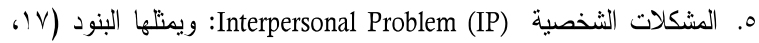

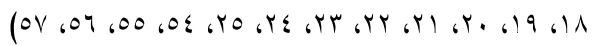

I. عدم الاستقرار العاطفى الانفعالى Emotional Lability (EL) : ويمثلها البنود

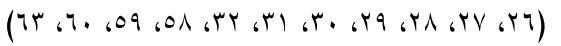

صدق وثبات المقياس:

1. ثبات المقياس: تم حساب معامل ثبات "مقياس المشكلات النفسية الاجنماعية"

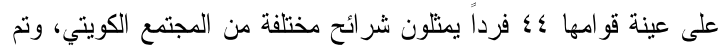

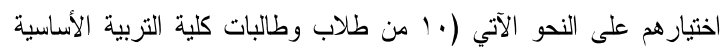
بدولة الكويت، وتم اختيارهم من كليات نظرية وعملية مختلفة، ويتراوح

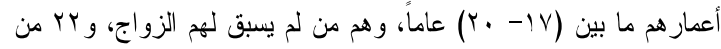

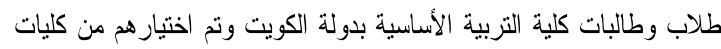

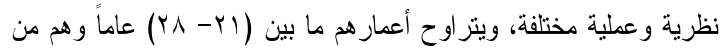

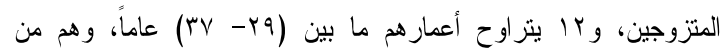

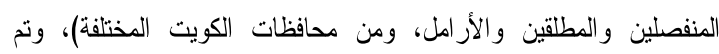
حساب معامل ثبات المقياس بطريقتى أعادة الاختبار و التجزئة النصفية ولئي

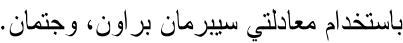
جدول (؛) يوضح معاملات ثبات مقياس المشكلات النفسية الاجتماعية لدى عينة الثقنين

\begin{tabular}{|c|c|c|c|}
\hline \multicolumn{2}{|c|}{ التجزئة النصفية } & \multirow{2}{*}{ أعادة التطبيق } & \multirow{2}{*}{ الأبعاد } \\
\hline جتمان & سبيرمان - براون & & \\
\hline$\cdot, i 1$ & • TV & $\cdot, \mathrm{V} r$ & مفهوم الذات (Sc) \\
\hline$\cdot, \mathrm{VV}$ & $\cdot, V \varepsilon$ & $\cdot, 19$ & الانطو اء الذاتى (In) \\
\hline$\cdot, V Y$ & $\cdot, \wedge$. & י, Vi & الاغتراب- الملل \\
\hline$\cdot, \mathrm{V}$ & $\cdot, \mathrm{VA}$ & $\cdot$, A. & الغضب (Al) \\
\hline • & r & $\cdot, \lambda$. & المشكلات الشخصية (Ip) \\
\hline$\cdot, 10$ & $\cdot, 9$. & $\cdot, \lambda$. & عدم الاستثر ار الانفعالى (EL) \\
\hline
\end{tabular}

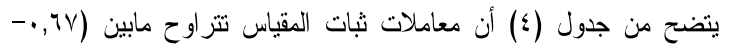

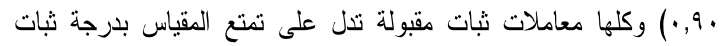

مرتفعة.

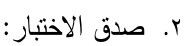

أ. الصدق التمييزى (المقارنة الطرفية): قام الباحث بحساب الصدق

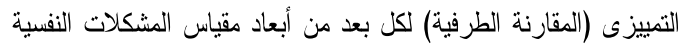

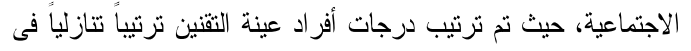

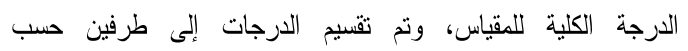

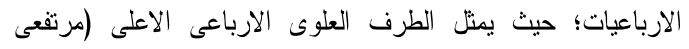

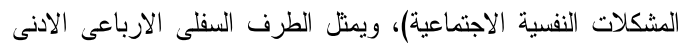

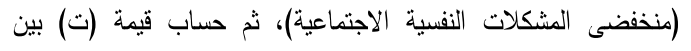
الطرفين و الجدول التالى يوضح نتائج المقارن الطرفية بين المجمو عتين. r. صدق الاختبار : لقد أصبح من الأمور المسلم بها فى مجال القياس النفسى أنه كلما تعددت الطرق المستخدمة فى التحقق من صدق الأداة؛ كان ذلك مدعاة الأن

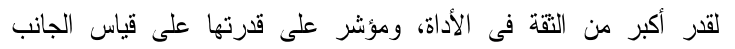

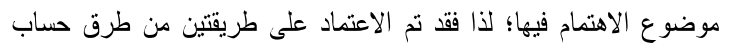

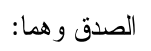

أ. الاتساق الداخلي: يعتمد صدق المقياس اعتماد مباشر على صدق

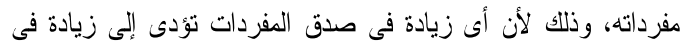

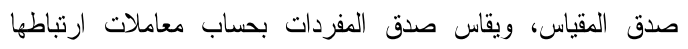

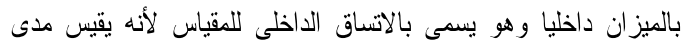

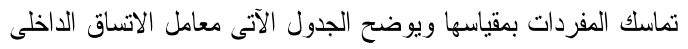

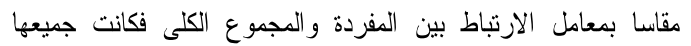

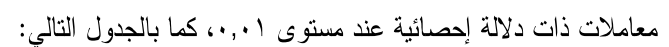

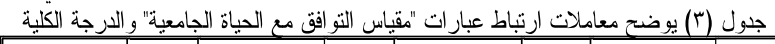

\begin{tabular}{|c|c|c|c|c|c|c|c|}
\hline معاملات & | العبارة | & $\begin{array}{l}\text { الارنباطات } \\
\text { معاملات }\end{array}$ & العبارة & معاماطلات & العبارة & الارنباطات & العبارة \\
\hline • $T \wedge V$ & YA & $\leqslant r \Lambda$, & 19 & . 1, & 1. & orr,. & 1 \\
\hline., $0 \leqslant 1$ & $r q$ & $\leq \leqslant \leftarrow$, & $r$. & م & 11 & $\leq \leqslant \wedge$, & $r$ \\
\hline$\cdot, i, 1$ & $r$. & $\cdot$, OYY & rI & $\left\{\mu_{\cdot, \cdot}\right.$ & Ir & or.,., & $r$ \\
\hline$\cdot, 0 \leqslant$ & r & . $\leqslant \leqslant 4$ & Yr & OVY, & $1 \pi$ & . & $\varepsilon$ \\
\hline י OY OY & $r$ & $\cdot, \leqslant \vee$. & r & TH,. & $1 \leqslant$ & $r \leqslant \vee$, & 0 \\
\hline - & זr &., 019 & $T \xi$ & oor,. & 10 & sor,. & 1 \\
\hline., $0 Y 1$ & $r \varepsilon$ & .,OHV & ro & $\{\wedge 1, \cdot$ & 17 & $001,$. & $\mathrm{V}$ \\
\hline., $0 \vee \leqslant$ & ro & $\cdot, \leqslant Y \wedge$ & ז & $\leqslant \mu_{\Lambda}$, & IV & $\{r,$. & $\lambda$ \\
\hline .,004 & 4 &., 019 & YV & OH,. & 11 & \& & 9 \\
\hline
\end{tabular}

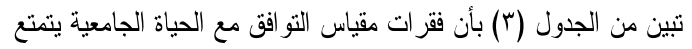

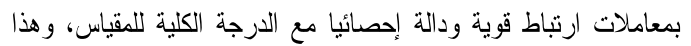

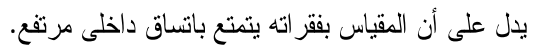

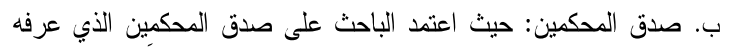

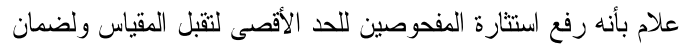

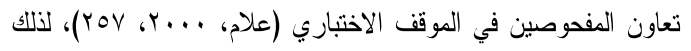

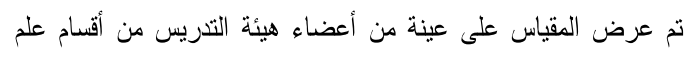

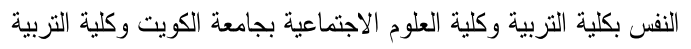

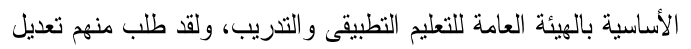

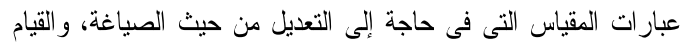

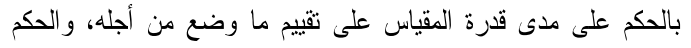

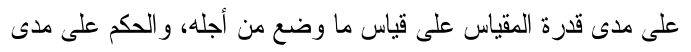

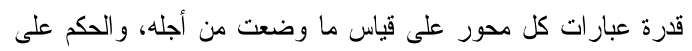

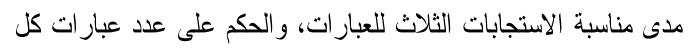
محور وعدد عبارات المقياس ككل، ولقد أسفرت عملية تحليل آراء

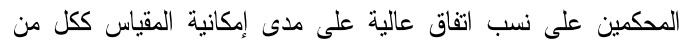

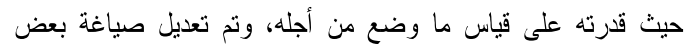

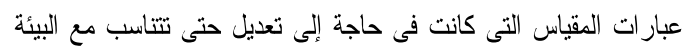
الكويتية، بناء على آراء المحكمين. 口 1 مقياس المشكلات النفسية الاجتماعية: أعد هذا المقياس عبدالرقيب البحيرى

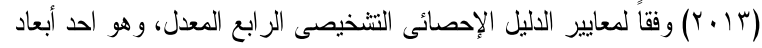

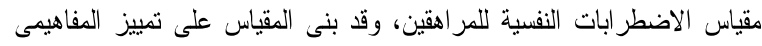

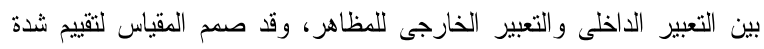

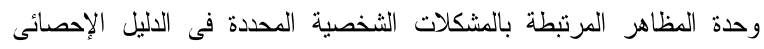

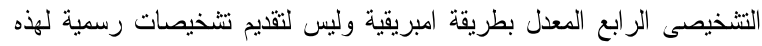

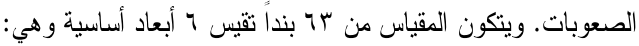




$$
\text { الذكور و الاناث على الاغتر اب و الملل. }
$$

وبناء على هذه النتائج الموضحة بالجدول السابق يمكن القول بقبول صحة

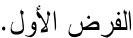

تعليق عام على نتائج الفرض الأول: يتضح من خلال تحليل نتائج الفرض الأول

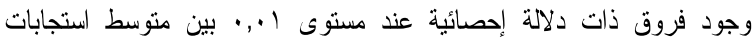
الذكور فى مقابل الاناث على مشكلات الانطواء على دلى الذات و المشكلات

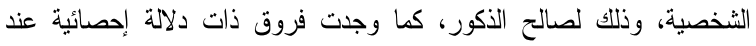
مستوى ا.,. بين متوسط استجابة الذكور فى مقابل الاناث على مشكلات

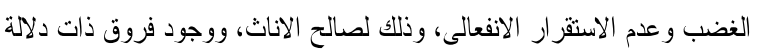

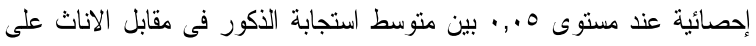

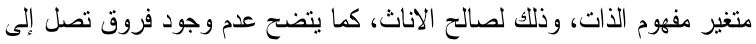
حد الدلالة بين متوسط استجابة الذكور و الاناث على الاغتر اب و الملان.

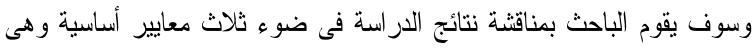

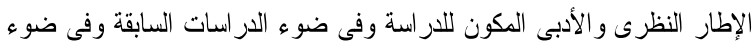

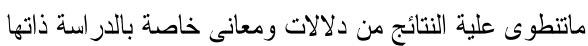

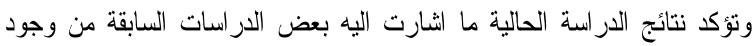

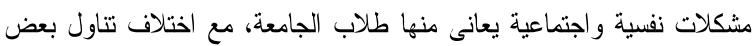

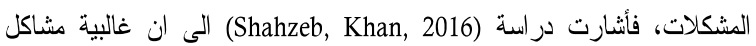

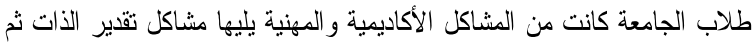

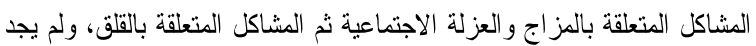
الباحث، فى حدود بحثه، أى دراسات تتاولت المقارنة بين طلاب الجامعة من لأن

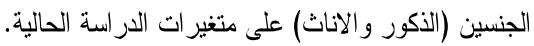

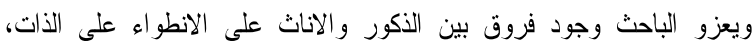

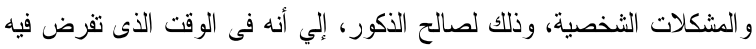

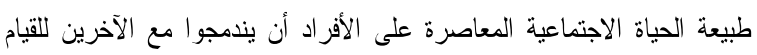

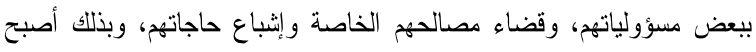

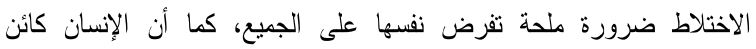
اجتماعي بطبعه، ولا يميل لكسر هذه القاعدة، فالميل الاجنماعي خاصية كامنة لاعنة

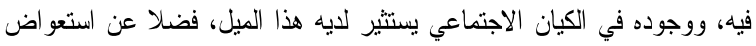

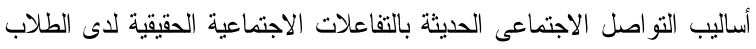

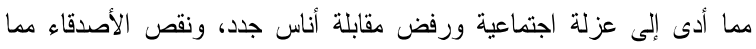

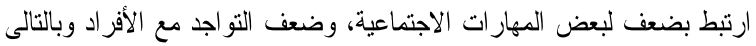

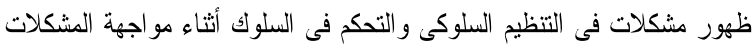

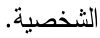

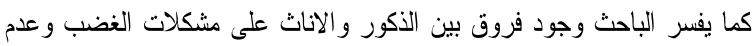

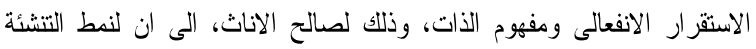

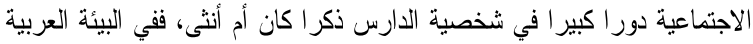

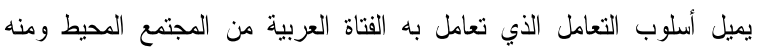

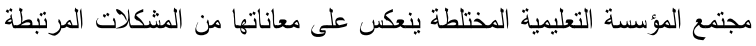

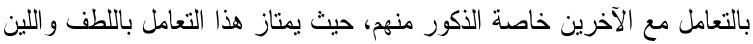

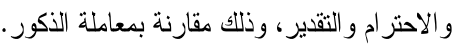
ويمكن تفسير ذلك أن الإناث أكثر توافقا مع الحياة الجامعية، نظراً لأنهن أكثر

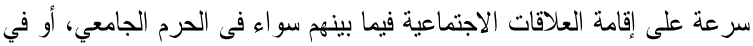

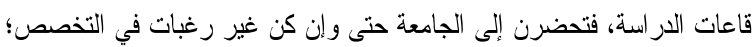

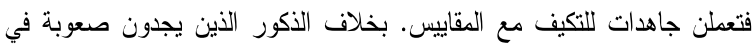

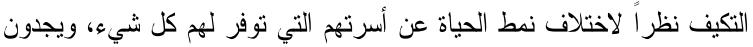
كل شيء جاهز، وسر عان ما يجدون أنفسهم مضطرين لتحضير كل مستلزماتهم

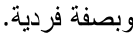

جدول (0) يوضح قيمة (ت) للفروق بين مرتفعى المشكلات النفسية الاجتماعية ومنخفىى المشكلات النفسية الاجتماعية لاى عبنة التقنين

\begin{tabular}{|c|c|c|c|c|c|c|}
\hline \multirow{2}{*}{ مستوى الدلة } & \multirow{2}{*}{ قات } & \multicolumn{2}{|c|}{ النفسية الاجتماعية الشكلات } & \multicolumn{2}{|c|}{ النفسية الاجتماعية المشكلات } & \multirow[t]{2}{*}{ أساليب المو اجهة } \\
\hline & & $\varepsilon$ & م & $\varepsilon$ & 5 & \\
\hline$\cdot, \cdot 0$ & $1 Y, V 4$ & $\{, 11$ & $r Y, \varepsilon \Lambda$ & 0,79 & $r \Lambda, \Lambda$ & مفهوم الذات \\
\hline$\cdot, \cdot 1$ & $1 Y, \cdot 0$ & $\{, \Lambda Y$ & $r r, \Lambda !$ & 0,04 & $\varepsilon \cdot, \cdot \varepsilon$ & الانطو اء على الذات \\
\hline$\cdot, \cdot 1$ & $1 \varepsilon, 9 \mathrm{~V}$ & $\{, \varepsilon)$ & $1 A, 10$ & $0, r_{1}$ & $r v, r q$ & الاغتر اب و الملل \\
\hline$\cdot, \cdot 1$ & $I V, \cdot V$ & $\{, 01$ & $\mid \mathrm{V}, \Delta \mathrm{V}$ & $0, \ldots$ & $r q, .$. & الغضب \\
\hline.,$\cdot 1$ & 11,79 & $\varepsilon, \cdots$ & $17, \varepsilon 0$ & $\varepsilon, \vee q$ & $r 4, \wedge 9$ & الشكلات الثخصية \\
\hline$\cdot, \cdot 1$ & 18,74 & $r, Y)$ & $15,9$. & $\{, r\}$ & $r \cdot, \cdot \varepsilon$ & عدم الاستثر ار الانفعالي \\
\hline
\end{tabular}

تبين من الجدول (0) أن معاملات الصدق التمييزى لأبعاد مقياس إدمان

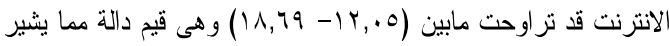

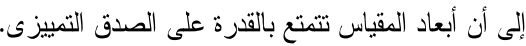
ب. صدق المحكمين: وفيه تم عرض المقياس على عينة من أعضاء هيئة التنريس من أقسام علم النفس بكلية التربية وكلية العلوم الاجتماعية

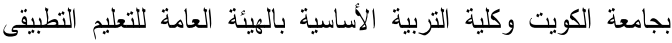

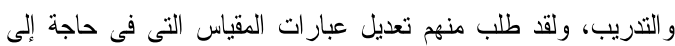

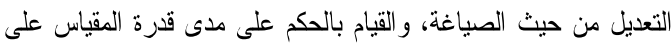

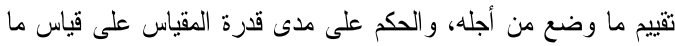

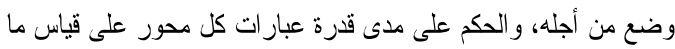
وضعت من أجله، والحكم على مدى مناسبة الاستجابات الثلاث

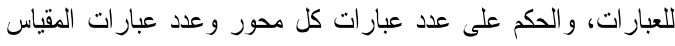

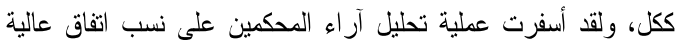

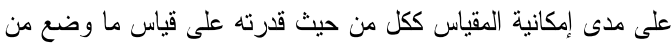

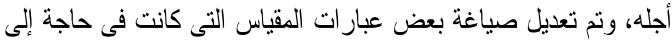

تعديل حتى تتناسب مع البيئة الكويتية، بناء على آراء المحكين.

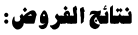

ه النتائج الخاصة بالفرض الأول: ينص هذا الفرض على انه تختلف المشكلات

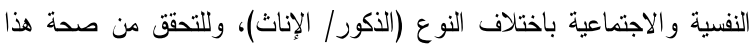

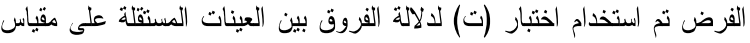
المشكلات النفسية الاجتماعية لدى عينة الدر اسة. جلول (") يوضح نتائج اختبار (ت) لعينتين مستقلتين بين الأكور والاناثة على مقياس المشكلات

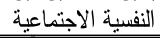

\begin{tabular}{|c|c|c|c|c|c|c|}
\hline \multirow{2}{*}{ الدسلة } & \multirow{2}{*}{ قاتمة } & \multicolumn{2}{|c|}{ الاناث(ن=V (1) } & \multicolumn{2}{|c|}{ 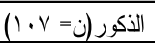 } & \multirow{2}{*}{ أساليب المو اجهة } \\
\hline & & $\varepsilon$ & ? & $\varepsilon$ & ? & \\
\hline., .0 & $r, 0.1$ & $r, 79$ & $1 y, 99$ & 1,90 & $1 V, 19$ & مفهوم الذات \\
\hline$\cdot, \cdot 1$ & $\{4,1 \%$ & 1,99 & $19,1$. & $\varepsilon, \wedge V$ & (r, & الانطو اء على الذات \\
\hline غير دالة & $\cdot, 0 Y 1$ & $r, \cdot \leq$ & $r 1,10$ & $r, \varepsilon r$ & $r 1,70$ & الاغتر اب و الملل \\
\hline$\cdot, \cdot 1$ & $7,\{04$ & r,or & $1 r, r$. & 1,70 & $1 \cdot, r 1$ & الغضب \\
\hline$\cdot, \cdot 1$ & rI, r,Y & $r, 91$ & $11, M$ & $0, r V$ & $r Y, Y)$ & المشكلات الشخصية \\
\hline$\cdot, \cdot 1$ & $0, \leq \leqslant 0$ & $r, 99$ & $|A, r|$ & $r, 4 \pi$ & $17,1$. & عدم الاستقر ار الانفعالي \\
\hline
\end{tabular}

يتضح من الجدول (7):

ا. وجود فروق ذات دلالة إحصائية عند مستوى ا.,.• بين متوسط استجابة

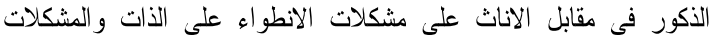

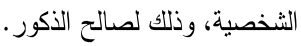
r. وجود فروق ذات دلالة إحصائية عند مستوى ال.,. بين متوسط استجابة ولابة

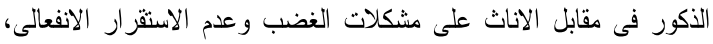
وذللك لصالح الاناث. r. وجود فروق ذات دلالة إحصائية عند مستوى ○.,. بين متوسط استجابة الذكور فى مقابل الاناث على متغير مفهوم الذات، وذللك لصالح الاناث. ؛. كما بتضح عدم وجود فروق تصل إلى حد الدلالة بين متوسط استجابة 
زوجها وأبنائها، خاصة مع انتشار الوعى فى المجتمع بأهية التعليم الجامعي،

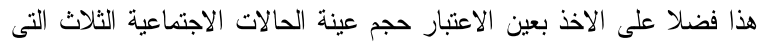

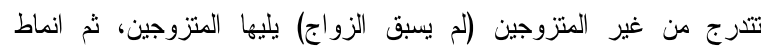

الانفصال الثثلاث.

口 النتائج الخاصة بالفرض الثالث: ينص هذا الفرض على انه "توجد علاقة ارتباطيه

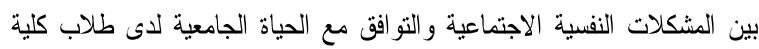

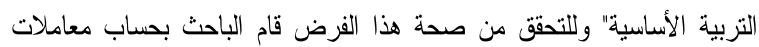

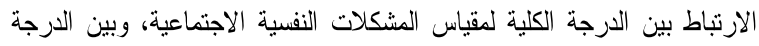

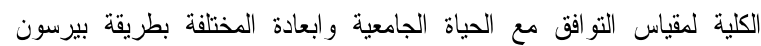

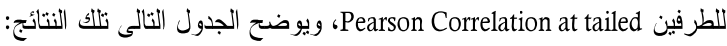

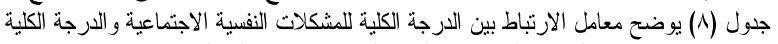

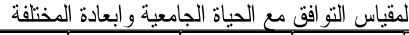

\begin{tabular}{|c|c|c|c|c|c|}
\hline لالدقاس الثق الفقلة & الالتز ام بتحقيق & الثخصي التق & الاجتماعي & الألتواديمي & البعد \\
\hline & & . & & $\star \star,, r>0$ & النفسية والاجتماعية المشكلات \\
\hline
\end{tabular}

الأثر

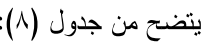

ا. عدم وجود علاقة ارتباطية بين الارجة الكلية لمقياس المشكلات النفسية الاجتماعية، و الدرجة الكلية لمقياس التو افق مع الحياة الجامعية.

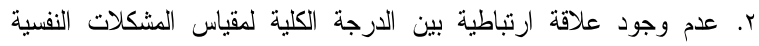

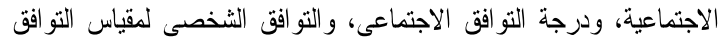
مع الحياة الجامعية. r. وجود علاقة ارتباطية موجبة عند مستوى ا+,. ب بين الدرجة الكلية لمقياس

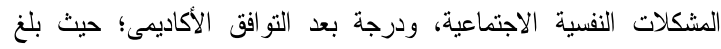

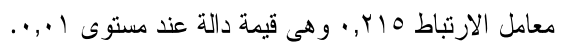

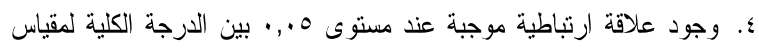

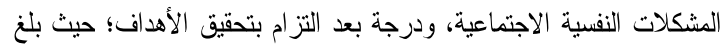
معامل الارتباط ـ10, • و هي قيمة دالة عند مستوى 0 .,.•.

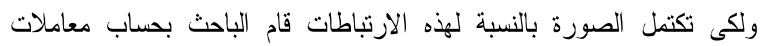

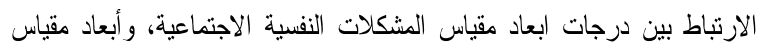

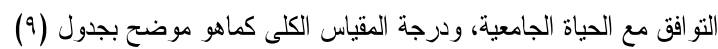

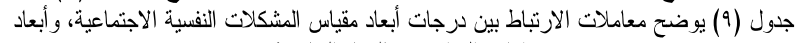

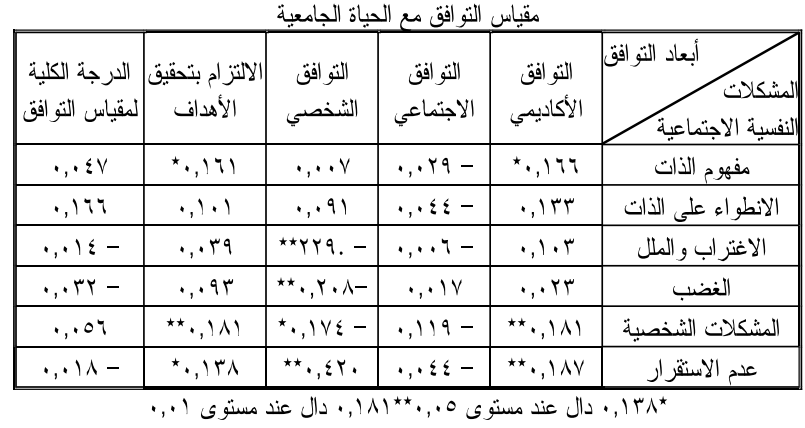

بتضح من جدول (9): (9)

1. وجود علاقة ارتباطية موجبة عند مستوى 0., بـ بين مشكلة مفهوم الذات

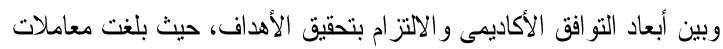

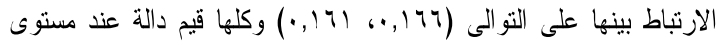

$. \cdot, \cdot 0$ r. عدم وجود علاقة بين مشكلة الانطواء وبين أبعاد التوافق الأكاديمى، الأبه،

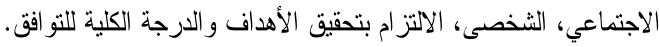

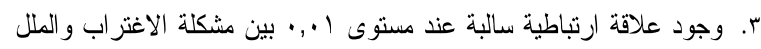

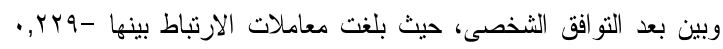

口 النتائج الخاصة بالفرض الثاني: ينص هذا الفرض على انه "تختلف المشكلات

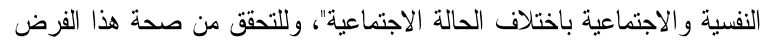

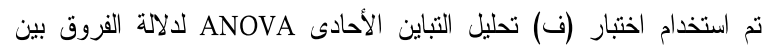

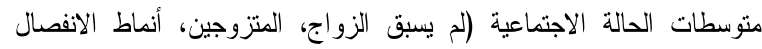

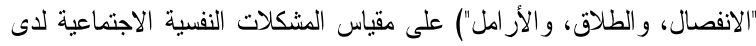

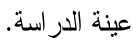

جدول (V) يوضح تحليل التباين الأحادى للكثف عن الفروق بين متوسطات الحالة الاجتماعية على الإيلى

\begin{tabular}{|c|c|c|c|c|c|c|}
\hline مستوى الدلالة & قيمة (ف) & متوبط & ב. & مجموع & مصدر التباين & ألواجهة \\
\hline \multirow{3}{*}{ غير دالة } & \multirow{3}{*}{ •, TVI } & $\Gamma, \wedge \varepsilon$ & $r$ & 8,79 & بين المجموعات & \multirow{3}{*}{ فهوم الذات } \\
\hline & & $0, V \mu$ & rII & $1, \cdot 9, \Gamma \xi$ & داخل المجمو عات & \\
\hline & & & TIT & $|r| Y, \cdot T$ & الكلي & \\
\hline \multirow{3}{*}{ غير دالة } & \multirow{3}{*}{$\cdot, 491$} & $09, \varepsilon V$ & $r$ & $111,9 \leq 9$ & بين المجموعات & \multirow{3}{*}{ على الأطوات } \\
\hline & & 101,91 & rII & rY. O $\leqslant, 10$ & داخل المجمو عات & \\
\hline & & & rir & rrIVT,l. & الكلي & \\
\hline \multirow{3}{*}{ غير دالة } & \multirow{3}{*}{$1,9 \ldots$} & $14, \lambda 9$ & $r$ & $r V, V A$ & بين المجموعات & \multirow{3}{*}{ والاغلت } \\
\hline & & $V, r)$ & rII & $10 \leqslant \mu, \leqslant 1$ & داخل المجمو عات & \\
\hline & & & rir & lovi,r. & الكلي & \\
\hline \multirow{3}{*}{ غير دالة } & \multirow{3}{*}{$\cdot,+Y Y$} &., 101 & $r$ &., 414 & بين المجموعات & \multirow{3}{*}{ الغضب } \\
\hline & & $7, \cdot \Gamma$ & rII & $|Y V Y, T|$ & داخل المجمو عات & \\
\hline & & & rir & IrVY,qT & الكلي & \\
\hline \multirow{3}{*}{ غير دالة } & \multirow{3}{*}{$\cdot, 17 \mathrm{~V}$} & $11, \lambda \varepsilon$ & $r$ & $r \mu, \Psi \Lambda$ & بين المجموعات & \multirow{3}{*}{ الثشخصية } \\
\hline & & $V_{\cdot}, \lambda$. & rII & $1 \leqslant 9 \leqslant \cdot, 0 r$ & ـاذل المجمو عات & \\
\hline & & & rir & $\mid \leq 97 \leqslant, Y)$ & الكلي & \\
\hline \multirow{3}{*}{ غير دالة } & \multirow{3}{*}{ -,$\leqslant 10$} & $r, r$. & $r$ & $8, \varepsilon 1$ & بين المجموعات & \multirow{3}{*}{ الاستثرار } \\
\hline & & $V, V Y$ & rII & $17 \pi \cdot \pi \varepsilon$ & داخل المجموعات & \\
\hline & & & rir & $174 \pi, 10$ & الكلي & \\
\hline
\end{tabular}

ويتضح من جدول (V) عدم وجود فروق تصل إلى حد الدلالة بين الطلاب ذوى

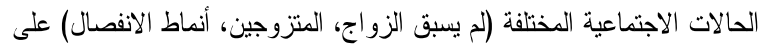

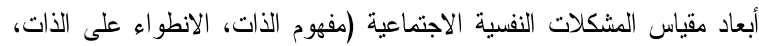

الاغتر اب و الملل، الغضب، المشكلات الشخصية، عدم الاستقرار).

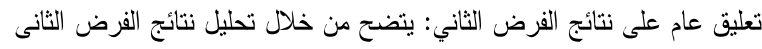

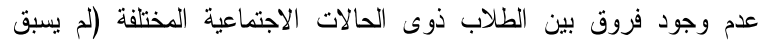

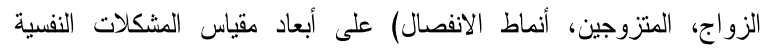

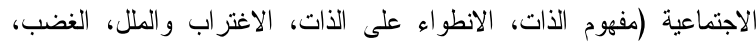
المشكلات الشخصية، عدم الاستقرار).

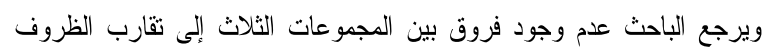

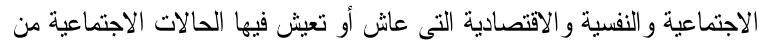

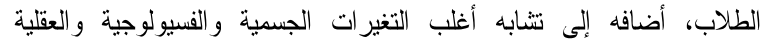

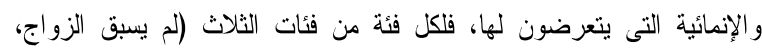

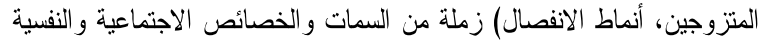

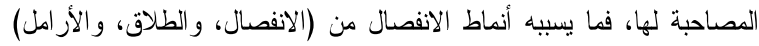

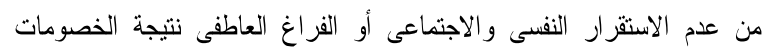

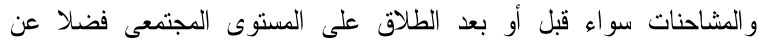
المستوى الأسرى، إضافة للتبعات المالية التى نترتب على حصول الطى الطلاق، يقابلة

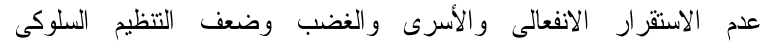

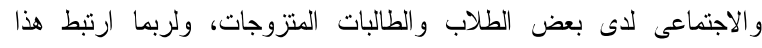
بالحساسية المرتفعة تجاه النقد، والاتجاه إلى تكوين مفهوم سلبى على التعليقات

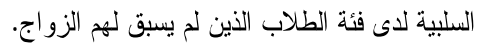

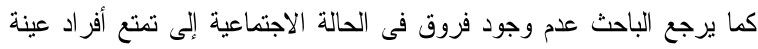

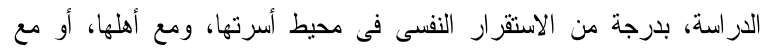


المستوى المادي و إعطاؤه المكانة الاجتماعية المرموقة، و إيجاد فرص عمل له، لذا

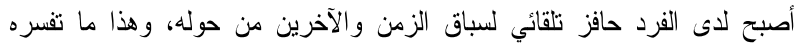

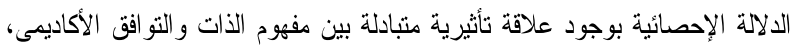

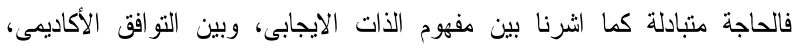

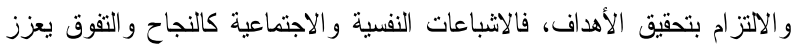

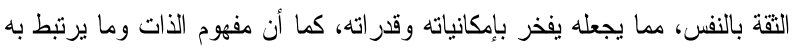

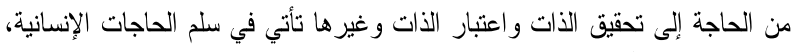
وفي التعليم غالباً ما يرتبط ذلك بالنجاح و التفوق، وكنلك من المهم للفرد رضاء

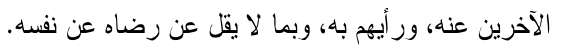

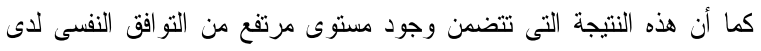

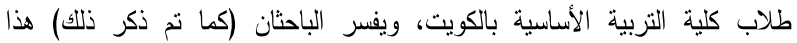

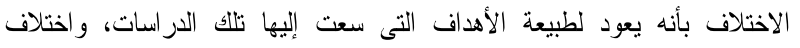

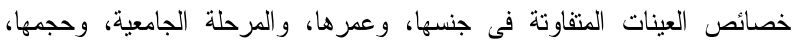

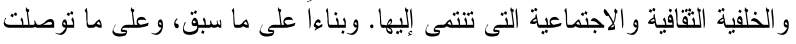
إليه نتيجة الفرض الثالث وجود علاقة موجبة أوسالبة بين بعض أبعاد المشكلات

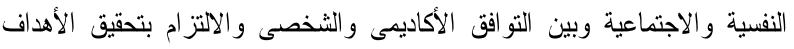
لاى طلاب كلية التربية الأساسية بالكويت، بتوفر عو امل من المتوقع أنها ساعدت ولإتئ

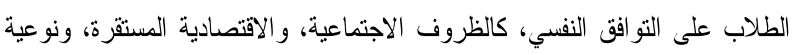

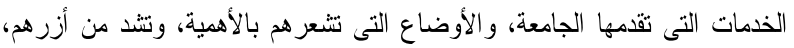

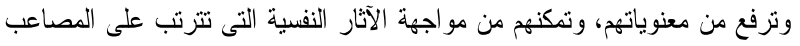

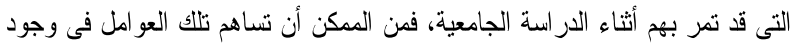

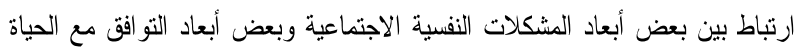

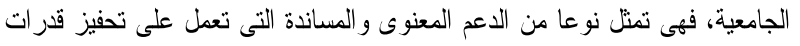

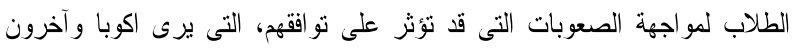
(Okubo, et.al, 2006)

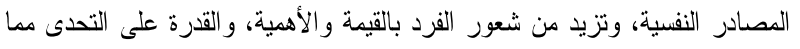

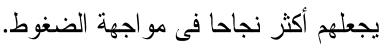
ومن ناحية أخرى أن تو افر بعض السمات الشخصية الإيجابية لدى الطلاب، تؤثر

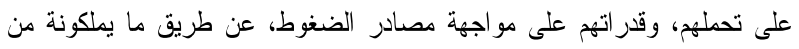

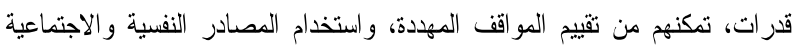

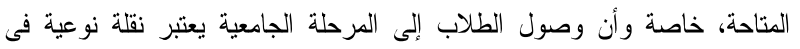

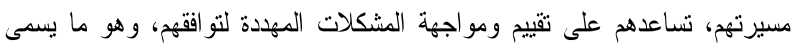
بالصلابة النفسية التى من أبرز مكوناتها (الالتز ام، التحكم، التحدي).

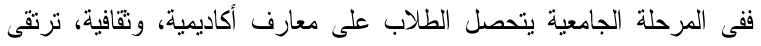
بفكرهن، وتمنحهن قدرا من التقة بالنفس، وقدرا من الحرية التى لم يعتدنها خلال

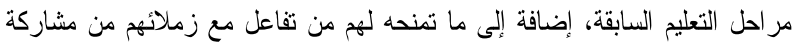

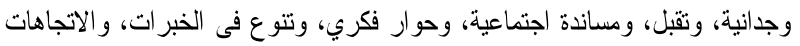

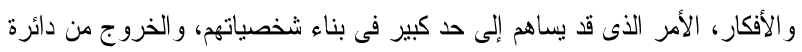

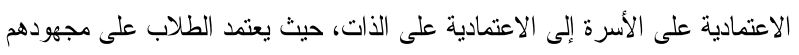

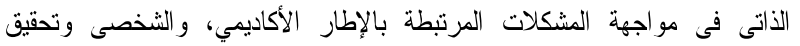

الأهداف المنشودة.

\section{مناقشة نتائج الدراسة:}

وجود فروق ذات دلالة إحصائية عند مستوى ل +, • بين متوسط استجابة الذكور

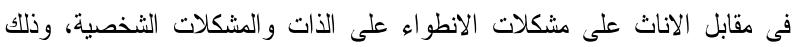

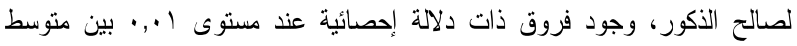

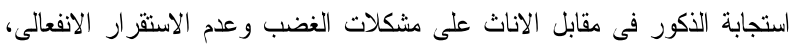

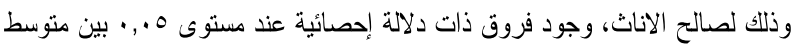

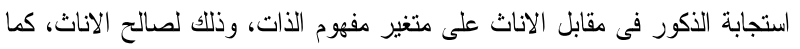

$$
\text { و هى قيمة دالة عند مستوى ا •,.•. }
$$

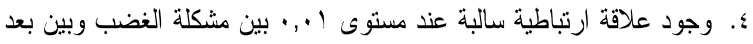

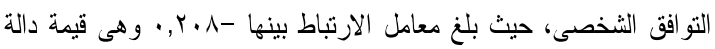

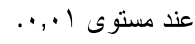

ه. وجود علاقة ارتباطية موجبة عند مستوى ا.,, بين المشكلات الثخصية

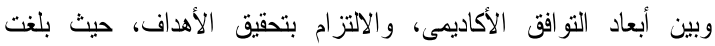

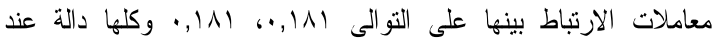

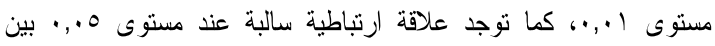
المشكلات الشخصية وبعد التو افق الثخصى، حيث بلغ معامل الارتباط بينها

$$
\text { I. }
$$

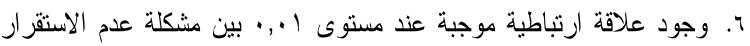

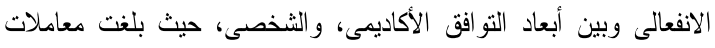

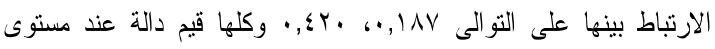

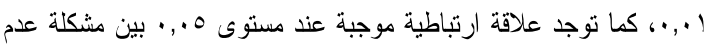

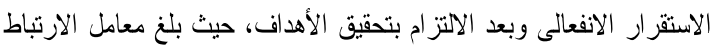

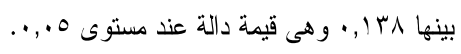

تعليق عام على نتائج الفرض الثالث: يتضح من خلال تحليل نتائج الفرض الثالث

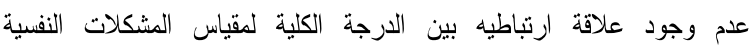

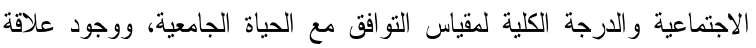

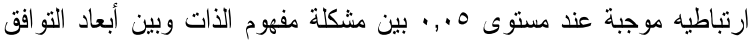

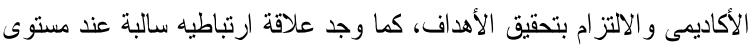

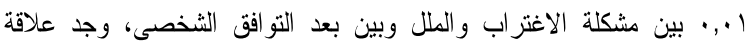

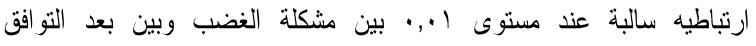

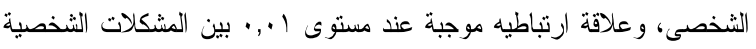

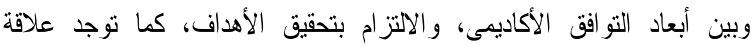

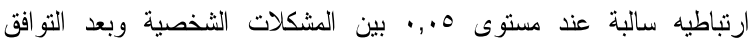

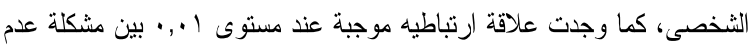

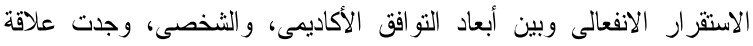

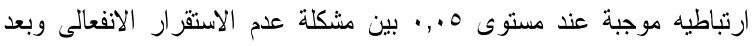

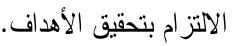
والمستقرئ لنتائج الدراسات السابقة يجد انها لم تهتم بدراسة العلاقة بين

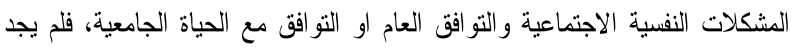

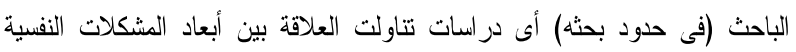

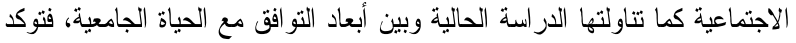

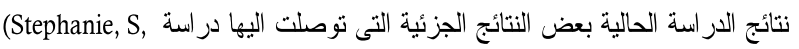

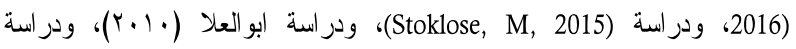

(Uguak, Elias, Uhi\& Suandi, 2006)

ويرى الباحثان أن الدراسة الحالية من أو ائل الدراسات التى اهتمت بدراسة أبعاد

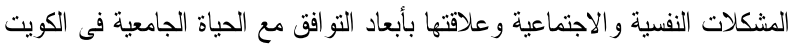

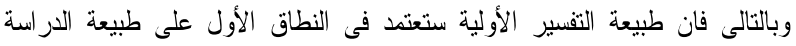

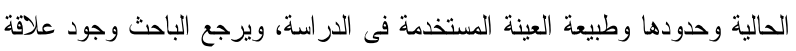

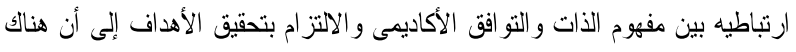

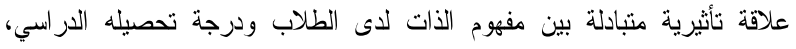

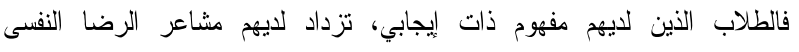

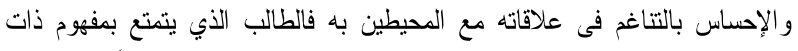

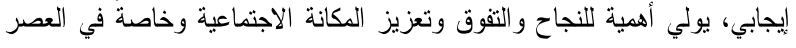

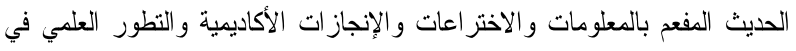
المجالات كافة، وحيث أخذت تتبلور أهمية العلم وماتتيحه للفرد من تحسين في 


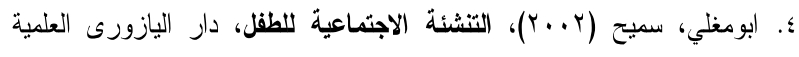

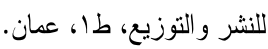

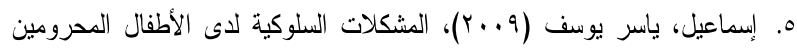

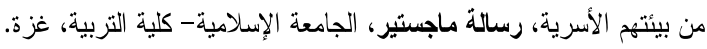

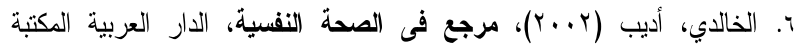

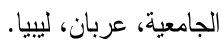

V. الرفاعي، نعيم (1991)،، الصحة النفسية دراسة في سيكلوجية التكيف، جامعة

دمثق، دمشق.

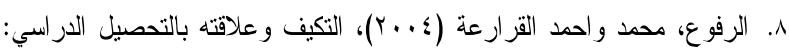

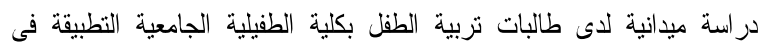

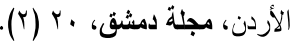

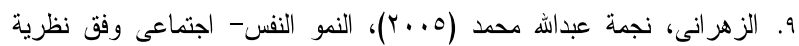
اريكسون وعلاقته بالتو افق و التحصيل الدراسى لدى عينة من طلاب وطالبات المرحلة الثانوية بمدينة الطائف، رسالة ماجستير غير ولئر منشورة، كلية التربية، جامعة أم القرى، المملكة العربية السعودية.

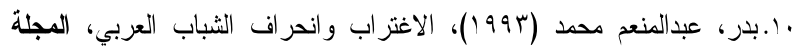

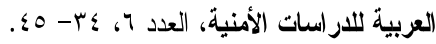

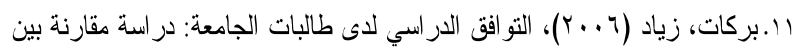

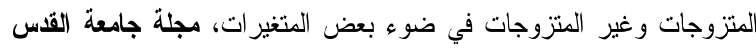

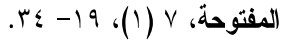

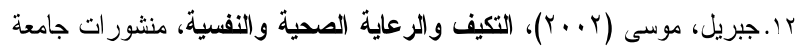
القدس المفتوحة، عمان

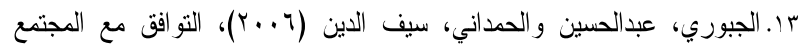

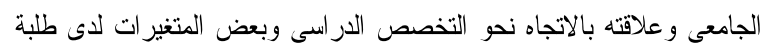

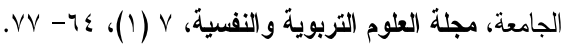

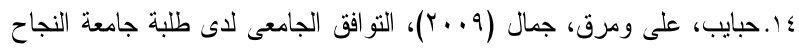

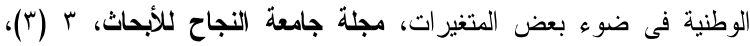

$. \wedge V q-\Lambda 0 V$

1. حسين، طه عبدالعظيم (Y..V)، استراتيجيات إدارة الغضب والعدوان، دار الفكر، عمان.

14.سلامة عبدالحافظ (Y. . . r)، علم النفس الاجتماعى، دار اليازوري، عمان.

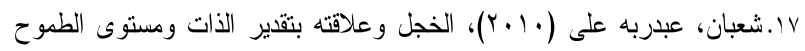

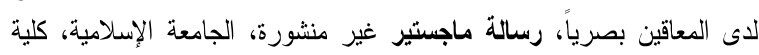

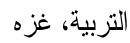

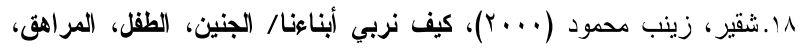
مكتبة النهضة المصرية، القاهرة.

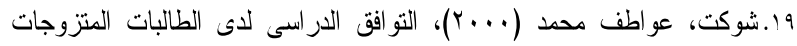

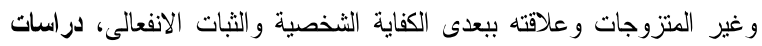

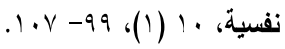

•r. عبد الحق، عماد حسين (9/9 (1)، المشكلات التكيفية التى تواجه طلبة الثانوية العامة فى المدارس الحكومية فى محافظة نابلس، رسالة ماجستير، جامعة النجاح

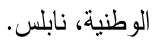

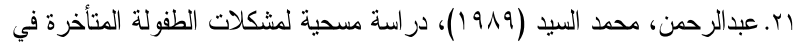
محافظة الثرقية، جامعة عين شمس، مركز دراسات الطفولة، المؤتمر السنوي

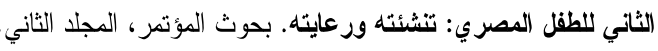

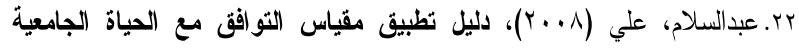
(ATCS)

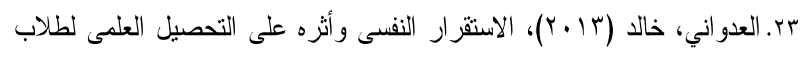

يتضح عدم وجود فروق تصل إلى حد الدلالة بين متوسط استجابة الذكور والاناث

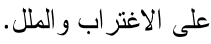

كما لم تؤيد نتائج الدراسة وجود فروق ذات دلالة إحصائية تصل إلى حد الدلالة

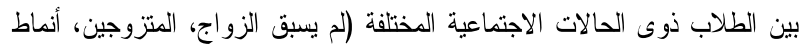

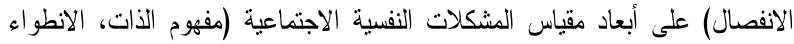

على الذات، الاغتر اب و الملل، الغضب، المشكلات الشخصية، عدم الاستقرار) .

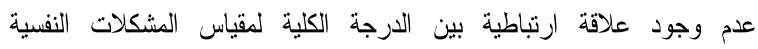
الاجتماعية و الدرجة الكلية لمقياس التو افق مع الحباة الجامعية، ووجودية علئ علاقة ارتباطية

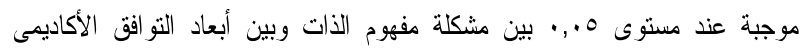

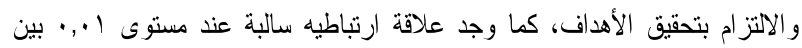

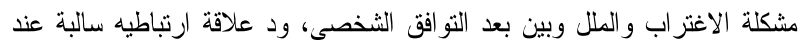

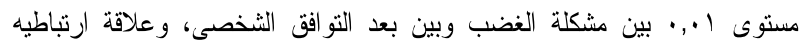

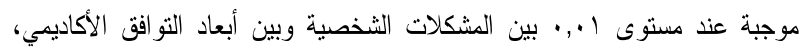

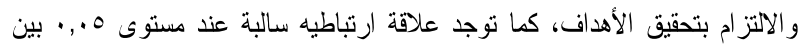
المشكلات الشخصية وبعد التوافق الثخصى، كما وجدت علاقة ارتباطيه موجبة عند الأدية

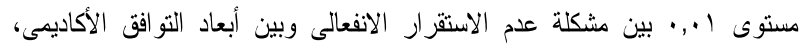

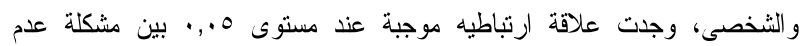

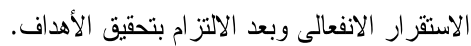

التوصيات:

I. تفعيل بر امج التوجيه و الارشاد النفسى والاجتماعى للطلبة المستجدين و الخريجين.

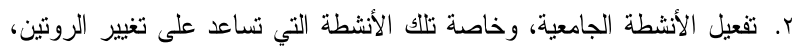

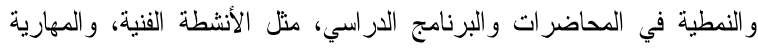

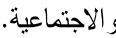

r. توعية الطلاب بمختلف المشاكل النفسية والاجتماعية و التعليمية التى يو اجهها

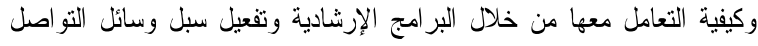
الاجنماعي.

؛. مشاركة الأسرة ممثلة فى الو الدين فى تهيئة أبنائهم للمرحلة التعليمية الجديدة،

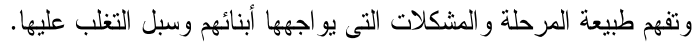

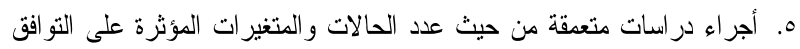

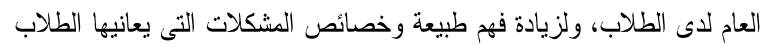

فى المرحلة الجامعية.

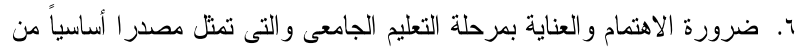

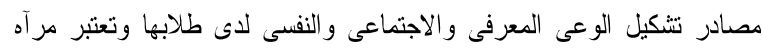
صادقة للمجتمع بكافة شر ائحه.

V. إجر اء دراسة مماثلة للتعرف علي أنماط المشكلات لاى فئات عمرية وتعليمية

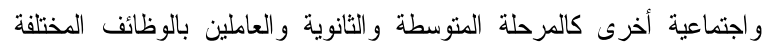
كالمدرسين وعمال المصانع، ... وغيرها.

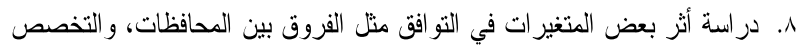

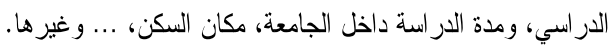

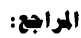

1. ابر اهيخ، رهام فرج (10 ب ب)، أهم المشكلات التي تو اجه الطالب الجامعى دراسة

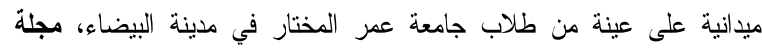

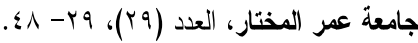

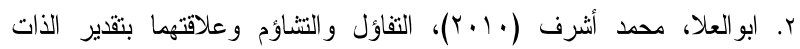

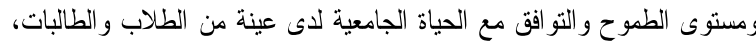

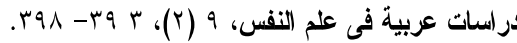

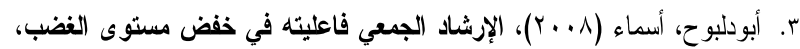

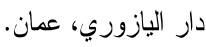


Achievement Amongst First Year Undergraduates In A Malaysian

Public University, International Journal of Arts and Sciences, 3 (11), 3 79- 392 .

40. Newman, P, H, R.\& Newman, B. M. (1981). Living the Process of

Adjustment, Howewlld, Illionis, Dorsy Pe

41. Okubo, T., Kurosawa, K.\& Kato, H. (2006). Person- Environment

Fit, Behavioral Orientation, and Subjective Adjustment: a Test of the Goodness- of- Hypothesis in University Students. Kagawa University, Toyo University, Tokoha Gakuen Junior College.

42. Paik, Chie\& Michael, William B. (2002). Further Psychometric Evaluation of the Japanese Version of An Academic Self Concept Scale. Journal of Psychology, 136 (3).

43. Perera, K. (2006), Self- Concept And Self- Esteem.

44. Ramos, S.\& Nicholas, L. (2007). Self Efficacy Of First Generation And Non First Generation College Students: The Relationship With Academic Performance And College Adjustment. Journal of College Counseling, 10 (1), 6 - 18.

45. Robazza, C, Laura, B. (2007). Perceived impact of Anger and Anxiety on Sporting Performance in Rugby Players. Psychology of Sport and Exercise, 6, 875- 896.

46. Shahzeb, S., Khan, N. (2016). C ommon Mental Health Problems in University Students: Exploratory Analysis, Journal of Behavioural Sciences, 26 (1), 3 12- 320.

47. Shields, N. (2002). A nticipatory Socialization, Adjustment To University Life, And Perceived Stress: Generational And Sibling Effects. Social Psychology of Education, 5, 365- 392.

48. Stephanie, S. (2016). Social Support, Self- Concept, Ethnic Identity, And College Adjustment Among Afro- Caribbean College Students, Unpublished Doctor Fordham University, New York.

49. Stoklose, M. (2015). College Student Adjustment: Examination Of Personal And Environmental Characteristics, Unpublished Doctor, School Of Wayne State University, Detroit, Michigan.

50. Uguak, U. A., Elias, H., Uli, J.\& Suandi, T. (2006). A cademic Adjustment and Psychological Well- Being among Students in an International School in Kuala Lumpur, Malaysia. Journal Pendidikan, Universti Malaya. 13 (2), 127- 139.

51. Wiersma, W. (1998). Research in Education: An Introduction, University of teledo, sixth edition

52. Wilson, B., (2005). Problem of University Adjustment Experieneed by Undergrand Uates in a Development Country. Jornal Higer Education, 13 (3), 154- 163.

53. Wilson, G, Paritchard, M.\& Yammitz, B. (2007)What predicts adjustment among college students? A longitudinal panel study. Journal of American college Health. 56(1), 15-21.
كلية التربية، مجلة الجامعة الإسلامية سلسلة الدراسات الإسانية، 19 (1)، .07V -0H

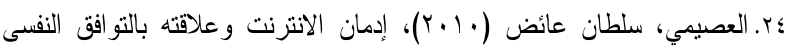

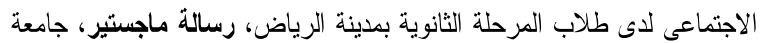

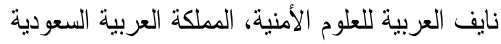

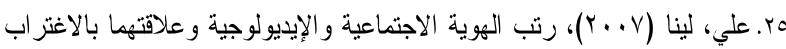

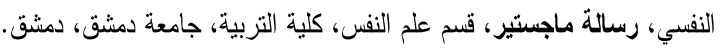

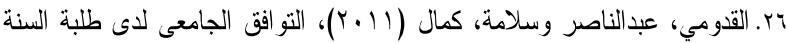

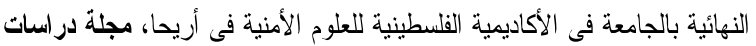

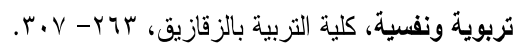
rV

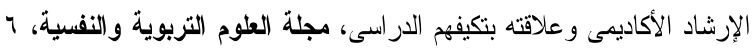

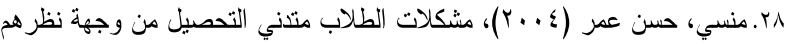
في كلية المعلمين بدحافظة الرس بالمملكة العربية السعودية، مجلة جامعة الملك

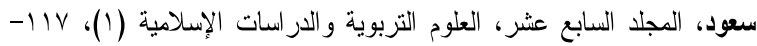
$.10 \mathrm{~V}$

9r.نعيسة، رغداء (Y Y.r)، الاغتراب النفسي وعلاقته بالأمن النفسي: دراسة

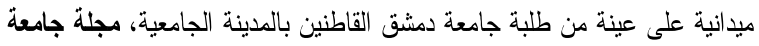

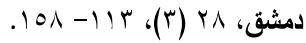

30. University Adjustment And Academic Achievement Amongst First Year Undergraduates In A Malaysian Public University, International Journal of Arts and Sciences, 3 (11), 3 79- 392.

31. Arkoff, A. (1968). Adjustment and mental health. New York: McGraw- Hill.

32. Backer, R. W., Siryk. (2010), Measuring Adjustment to College. Journal of Counseling Psychology, 31 (3), 2 14- 223.

33. Baker, S. R. (2003). A prospective longitudinal investigation of social problem solving appraisals on adjustment to university, stress, health, and academic motivation and performance. Personality and Individual Differences, 35 (3), 569- 591.

34. Banu, B\& Sibnath, D. (2015). P erceived Academic Stress Of University Student Across Gender, Academic Streams, Semesters, And Academic Performance. Indian Journal of Health and Wellbeing, 6 (3), 231-235.

35. Chen, Jesse. (2016). M ultidimensional Approach To Predicting Freshman College Adjustment Unpublished Doctor, Fairleigh Dickinson University. http://www.more-selfesteem.com/selfconcept. com

36. Mahyuddin, R, Abdullah, M, Elias, H, Uli, J. (2010). Relationship Between Coping.

37. Mehdizadeh, N.\& Scott, G. (2005). Adjustment Problems of Iranian International Students in Scotland. Scotland: Shannon Research Press International Education Journal, 6 (4), 484- 493.

38. Mewett, Helen, F. (2016). International Students and Mental Health, Journal of International Students, 6 (3), 661- 677.

39. Mahyuddin, R, Abdullah, M, Elias, H, Uli, J. (2010). Relationship Between Coping And University Adjustment And Academic 